Estudios sobre armas antiguas, arte militar y vida cultural en oriente y occidente XXX III (2013), pp. 131-156

ISSN : 0436-029X

doi: 10.3989/gladius.2013.0006

\title{
CATEGORÍAS DE COMBATIENTES Y SU ARMAMENTO EN EL ARAGÓN BAJOMEDIEVAL: LA GUERRA DE LOS DOS PEDROS (1356-1366)
}

\author{
CATEGORIES OF COMBATANTS AND THEIR ARMAMENT IN THE KINGDOM OF ARAGON \\ IN THE LATER MIDDLE AGES: THE WAR OF THE TWO PEDROS (1356-1366)
}

POR

\author{
Mario Lafuente GómeZ*
}

\section{RESUMEN - ABstract}

En este artículo, se analizan algunas de las condiciones técnicas en las que se desarrolló la guerra de los Dos Pedros, conflicto que enfrentó a las monarquías aragonesa y castellana entre 1356 y 1366. Para ello, se presenta una definición de las principales categorías de combatientes integradas en el ejército aragonés y, seguidamente, se ofrece una detallada descripción del equipamiento asociado a cada una de ellas. La tesis general sobre la que se apoya el trabajo entiende que, desde el punto de vista técnico, la guerra de los Dos Pedros se sitúa en los albores de la llamada revolución militar, ya que, durante este conflicto, se manifestaron en paralelo formas y técnicas de combate tradicionales, como el asedio de las fortificaciones y las cabalgadas, junto a ciertos elementos que preludiaban ya la praxis de la guerra moderna, entre los que cabe destacar el uso de la pólvora.

In this article, we analize the tecnical conditions of the armament employed in the War called «of the Two Pedros», an important conflict developed between the monarchies from Aragon (Pedro IV) and Castille (Pedro I), between 1356 and 1366. In order to do it, we offer a definition about the main categories of combatants in the Aragonese army and, after it, we describe their equipment. Our thesis argues that, in a thecnical sense, this war can be considered as a prelude of the Military Revolution in the Crown of Aragon, because of, during the conflict, the Aragonese army employed traditional kinds of combat (large sieges and short attacks to capture people and things) and, also, little technical changes, like the use of gunpowder.

\section{Palabras Clave - Keywords}

Guerra; Reino de Aragón; Baja Edad Media; Combate; Armamento; Revolución militar.

War; Kingdom of Aragon; Later Middle Ages; Combat; Armament; Military Revolution.

* Facultad de Filosofía y Letras, Departamento de Historia Medieval, Ciencias y Técnicas Historiográficas y Estudios Árabes e Islámicos, Universidad de Zaragoza, mariolg@unizar.es. Este trabajo forma parte de la actividad desarrollada por el Grupo de Investigación consolidado CEMA de la Universidad de Zaragoza, que financia el Gobierno de Aragón y dirige el Dr. José Ángel Sesma Muñoz. Sitio web: cema.unizar.es. Siglas y abreviaturas utilizadas: ACA (Archivo de la Corona de Aragón), R.Pat. (Real Patrimonio), M.Rac. (Maestre Racional), Canc. (Cancillería), reg. (registro), AHPrNtZ (Archivo Histórico de Protocolos Notariales de Zaragoza), ACRA II (Acta Curiarum regni Aragonum, Cortes de Pedro IV/1, t. II, eds. J. Ángel Sesma Muñoz y Mario Lafuente Gómez, Grupo CEMA, Gobierno de Aragón, Cortes de Aragón e Ibercaja, Zaragoza, 2013), ACRA III (Acta Curiarum Regni Aragonum, Cortes del reinado de Pedro IV/2, ed. C. Laliena Corbera, Grupo CEMA, Gobierno de Aragón, Cortes de Aragón e Iber Caja, Zaragoza, 2008). 


\section{INTRODUCCIÓN: LA PRAXIS DEL COMBATE EN LOS ALBORES DE LA REVOLUCIÓN MI- LITAR}

Para la cultura occidental contemporánea, existen pocas dudas de que la guerra, en cualquiera de sus manifestaciones, fue uno de los ejes en torno a los que se construyó el mundo medieval. En efecto, combatientes a caballo, castillos, ballesteros, cruzados y torneos, entre otros muchos elementos, han sido y son iconos fuertemente enraizados en el imaginario colectivo desde, al menos, 1819, cuando el escocés Walter Scott publicó su aclamada novela Ivanhoe. Esta obra, de naturaleza e inspiración típicamente románticas, consigue trasladar al lector hasta la Inglaterra del siglo XII y sumergirle en una historia armoniosamente compuesta, en la que no faltan la pasión, el valor, la magia ni, por supuesto, la guerra. Desde entonces y hasta hoy, la literatura no ha dejado de recrear aquella imagen y, más recientemente, la cultura audiovisual ha multiplicado exponencialmente la cantidad de señales de todo tipo que, de uno u otro modo, se inspiran en ella para reproducir una idea de la Edad Media que ciertamente se ha convertido ya en un tópico ${ }^{1}$.

Pero la utilización de la guerra como metonimia del pasado, en el sentido que remite al uso de la parte por el todo, no se produce únicamente al representar el Medievo. De hecho, muchas otras épocas son imaginadas, e incluso llegan a despertar fascinación, precisamente a partir de las grandes contiendas que en ellas se produjeron ${ }^{2}$. El origen de esta representación es, qué duda cabe, esencialmente cultural, ya que, como sintetizó con agudeza Benedetto Croce, el modo en que una sociedad percibe el pasado forma parte de su propia concepción de la realidad y, generalmente, las categorías con las que lo representa irradian de su propio utillaje mental $^{3}$. En este sentido, se puede afirmar que si la guerra es una de las categorías más utilizadas para representar a las sociedades que nos precedieron, no es porque en el pasado se combatiera más que en el presente, sino porque, de alguna manera, el fenómeno guerra -parafraseando a Gaston Bouthoul- es lo suficientemente atractivo en sí mismo como para captar y mantener toda nuestra atención ${ }^{4}$. La guerra como juego o como fiesta es y siempre ha sido un espectáculo, quizás porque permite vivir, aunque sea en la piel de otro, la experiencia suprema de poner en riesgo la propia vida ${ }^{5}$.

Ese poder de seducción que sobre la posteridad ejerce todo lo que tiene que ver con la guerra se canaliza y se pone de manifiesto, habitualmente, a través de la toma de contacto con la praxis del combate, mediante la reproducción de elementos materiales y prácticas verosímiles, aunque no necesariamente históricas. Así es como la forma de la guerra pasa a identificarse

1 La representación del mundo medieval en la cultura contemporánea cuenta con numerosos estudios, entre ellos los de Régine Pernoud, Para acabar con la Edad Media, Medievalia, Palma de Mallorca, 2003 (ed. or. 1977); Jacques Heers, La invención de la Edad Media, Crítica, Barcelona, 1995 (ed. or. 1992); Alain Guerreau, El futuro de un pasado. La Edad Media en el siglo XXI, Crítica, Barcelona, 2002 (ed. or. 2001); Jacques Le Goff, En busca de la Edad Media, Paidós, Barcelona, 2003; Julio Valdeón Baruque, "La valoración histórica de la Edad Media: entre el mito y la realidad", Memoria, mito y realidad en la Historia Medieval, XIII Semana de Estudios Medievales de Nájera, Instituto de Estudios Riojanos, Logroño, 2003, pp. 311-329; Juan José Carreras Ares, "Edad Media, instrucciones de uso", Revista de Historia Jerónimo Zurita, 82 (2007), pp. 11-26; y la obra colectiva La Historia Medieval hoy: percepción académica y percepción social, XXXV Semana de Estudios Medievales de Estella, Gobierno de Navarra, Pamplona, 2009.

2 Leonard M. Dudley, The Word and the Sword. How techniques of Information and Violence Have Shaped our World, Cambridge, Mass, Blackwell, 1991, pp. 101-131.

3 "Los requerimientos prácticos que laten bajo cada juicio histórico dan a toda la historia carácter de historia contemporánea". Benedetto Croce, La historia como hazaña de la libertad, Fondo de Cultura Económica, México, 1990, p. 11. Cita Santos Juliá, Elogio de Historia en tiempo de Memoria, Marcial Pons, Madrid, 2011, p. 108.

4 La paráfrasis alude al título de la clásica obra de Gaston Bouthoul, Le Phénomène-Guerre, Payot, 1962.

5 Franco Cardini, Quella antica festa crudele. Guerra e cultura della guerra dall'età feudale alla grande rivoluzione, Sansoni Editore, Firenze, 1982, p. 14. 
con la forma del pasado y su capacidad de atracción termina por mediatizar todo el pensamiento histórico ${ }^{6}$. Este proceso es bien conocido por aquellos investigadores que se han adentrado, de uno u otro modo, en el estudio de la técnica militar en la Edad Media, un campo especialmente mistificado en la época contemporánea debido, sobre todo, a la acción de los grandes medios de comunicación y a su enorme influencia sobre el imaginario colectivo. Deconstruir y corregir esa imagen ficticia de la guerra medieval es un objetivo excesivo y, seguramente, poco realista, para el reducido círculo de especialistas en aquello que John Keegan denominó «el rostro de la batalla ${ }^{7}$. Con todo, si el reto se planteara, la única estrategia eficaz pasaría por integrar, con naturalidad, el estudio de los elementos técnicos de la guerra medieval en las líneas de investigación más recientes dentro de la Historia económica y social ${ }^{8}$.

Con esta última reflexión como horizonte teórico, este trabajo aborda el estudio de la técnica militar empleada por las compañías puestas al servicio del rey de Aragón, Pedro IV, en el contexto de la guerra que sacudió a las Coronas aragonesa y castellana en las décadas centrales del siglo XIV, la llamada guerra de los Dos Pedros (1356-1366). Más concretamente, su contenido está orientado hacia la explicación, primero, de las diversas categorías de combatientes, tanto a caballo como a pie, y, en segundo lugar, de los elementos materiales que componían el arnés de cada uno de ellos, su valor material y su interpretación cultural.

Para indagar en todas estas cuestiones conviene introducir aquí un planteamiento historiográfico que ha servido, en las últimas décadas, para explicar la evolución del ejercicio de la guerra entre los dos últimos siglos de la Edad Media y el comienzo de la época moderna. Nos referimos a la revolución militar, proceso en el cual se engloban una serie de transformaciones progresivas que afectaron al modo en que se organizaron los ejércitos europeos desde, aproximadamente, las décadas centrales del siglo $\mathrm{XIV}^{9}$. Si bien es cierto que el funcionamiento general del ejército en combate no cambió, en lo sustancial, a lo largo de la Edad Media, no lo es menos que, con el inicio de la guerra de los Cien Años, por mencionar un espacio y un tiempo determinados, se comenzaron a dar en Europa los primeros pasos hacia lo que podemos denominar la organización militar propia del Estado moderno. Estas novedades, según Clifford Rogers, se pueden agrupar en torno a cuatro grandes conceptos: la aparición de las fortificaciones de defensa activa, la utilización de la infantería de modo cada vez más eficaz, la introducción de las armas de fuego y, por último, la burocratización de los ejércitos y su progresiva conversión en estructuras permanentes.

Buena parte de las transformaciones que acabamos de enunciar se forjaron en torno a la preparación y ejecución de campañas a medio plazo, mayoritariamente en el contexto del conflicto anglofrancés, y que incluyeron, generalmente, grandes sitios y populosas batallas campales $^{10}$. La guerra de los Dos Pedros se desarrolló, sin embargo, con un guión sensiblemente

\footnotetext{
6 Hayden V. White, El contenido de la forma. Narrativa, discurso y representación histórica, Paidós, Barcelona, 1992; y, más recientemente, Jaume Aurell, "El nuevo medievalismo y la interpretación de los textos históricos", Hispania, vol. LXVI, núm. 224 (sep-dic 2006), pp. 809-832.

7 John Keegan, El rostro de la batalla, Ejército, Madrid, 1990.

8 Véanse, por ejemplo, las reflexiones al respecto de Christiane Raynaud (dir.), Armes et outils, Le Léopard d'Or, Paris, 2012, pp. 7-23 (Introducción).

9 Desde el punto de vista científico, el conocimiento estas transformaciones es cada vez más preciso gracias no sólo al trabajo de los historiadores, sino también a las aportaciones que otras disciplinas, como la arqueología o la iconografía, han sido capaces de realizar. Para el contexto tecnológico de la guerra de los Dos Pedros, véanse las siguientes obras: Clifford J. Rogers, "The Military Revolutions of the Hundred Years War", The military revolution debate: readings on the military transformation of early modern Europe, ed. C. J. Rogers, Oxford, 1995, pp. 55-93; Jim Brandbury, The Medieval Siege, Woodbridge, 1992; y Geofrey Parker, La Revolución Militar. Las innovaciones militares y el apogeo de Occidente, Crítica, Barcelona, 1990.

10 Jonathan Sumption, The Hundred Years War I. Trial by Battle, University of Pennsylvania Press, Philadelphia, 1999 (ed. or. 1990); y, del mismo autor, The Hundred Years War II. Trial by Fire, University of Pennsylvania Press, Philadelphia, 1999.
} 
distinto. Los tipos de combate que predominaron durante el conflicto hispánico, especialmente desde el lado aragonés, fueron, por un lado, el asedio y defensa de fortificaciones y, por otro, la ejecución de cabalgadas y ataques esporádicos de carácter depredador. No existieron grandes campañas en la Península Ibérica entre 1356 y 1366, comparables a las inglesas en Crècy o Calais, y tan sólo la gran ofensiva castellana de 1362-1363 se podría comparar a aquellas. Asimismo, tampoco se produjeron grandes batallas campales durante la guerra de los Dos Pedros, sino que las acciones predominantes consistieron en hechos de armas de pequeña escala, donde la captura de botín y cautivos era el objetivo prioritario ${ }^{11}$.

Las características propias del conflicto hispánico condicionaron, pues, el paulatino desarrollo de los cambios asociados a la revolución militar en el reino de Aragón y, por extensión, en el resto de la Península Ibérica. El más importante de todos ellos se encuentra en el ámbito de la arquitectura militar y de la poliorcética, dado que, como acabamos de indicar, el asedio y la defensa de fortificaciones constituyó el modus operandi esencial de los ejércitos aragonés y castellano entre 1356 y 1366 . Las transformaciones en este campo se insertan en un proceso de larga duración, iniciado al filo de 1300, cuando la arquitectura militar en el Occidente medieval hubo de enfrentarse a máquinas de asedio cada vez más potentes. Este proceso ha sido definido como de transición desde un sistema defensivo "pasivo», donde había prevalecido el criterio del castillo refugio, asociado estéticamente al mundo románico; a una técnica de defensa «activa», en el que el castillo se iría dotando ya de medios materiales para facilitar el ataque desde el mismo, y que ha sido inscrito por su morfología en el mundo gótico.

Las transformaciones en la hechura de las fortalezas se pueden resumir en seis puntos: reubicación de las torres del homenaje junto a la muralla, en lugar de situarse en el centro, y el trazado de las mismas sobre plantas poligonales; multiplicación de torres adosadas al paño de las murallas, algunas de ellas de planta circular (los cubelos); introducción y generalización de sistemas de tiro vertical (por ejemplo, los balcones con matacanes); aparición de barbacanas (paños de muralla no cerrados sobre sí mismos) parciales o extensas; encuadramiento de las puertas entre torreones u otros medios para facilitar su defensa; y alargamiento de los adarves (caminos de ronda) y nuevos diseños de los merlones (por ejemplo con saeteras) ${ }^{12}$. Todos estos elementos formaban parte de la estructura más sólida de cada fortaleza, estaban construidos con materiales pétreos y solían servir como plataforma para el levantamiento de otras construcciones menos consistentes pero igualmente eficaces. Entre ellas, merece la pena destacar las verdescas, terrazas de madera asentadas en altura sobre la cara exterior de los muros, desde las cuales se podía atacar en oblicuo, o incluso en vertical, a los sitiadores de la fortificación.

La importancia medular del asedio y defensa de las fortificaciones entre las técnicas de combate desarrolladas en la guerra de los Dos Pedros condicionó, a su vez, el desarrollo de otras novedades asociadas a la revolución militar de la Baja Edad Media. Así, el creciente peso

11 El desarrollo de la guerra puede seguirse en Mario Lafuente Gómez, Dos Coronas en guerra. Aragón y Castilla (1356-1366), Grupo Cema-Universidad de Zaragoza, Zaragoza, 2012.

12 João Gouveia Monteiro, Os castelos portugueses dos finais da Idade Média: presença, perfil, conservaçao, vigilância e comando, Ed. Colibrí-Univ. De Coimbra, Lisboa, 1999, pp. 34-35; Richard L.C. Jones, "Fortalezas y asedios en Europa occidental c. 800-1450", Historia de la guerra en la Edad Media, ed. M. Keen, Antonio Machado Libros, Madrid, 2005 ( $1^{\text {a }}$ ed. 1999), pp. 211-238. Sobre la ejecución de la guerra en la Edad Media, mediante el cerco y la defensa de los castillos, Stewart Bachrach, "Medieval Siege Warfare: a Reconaissance", The Journal of Military History, 58-1 (ene 1994), pp. 119-133; Aldo A. Settia, "Il reflesso ossidionale", Uomini contro. La guerra nel Medioevo, Roma-Bari, 2002, pp. 77-182; Francisco García Fitz, "Guerra y fortificaciones en contextos de frontera. Algunos casos ibéricos de la Plena Edad Media”, Mil Anos de Fortificações na Península e no Magreb (500-1500). Actas do Simposio Internacional sobre Castelos, Lisboa, 2002, pp. 519-532; y Luis Miguel Duarte, "Un país de besteiros e castelos (a guerra em Portugal na Baixa Idade Média)”, en Guerra y diplomacia en la Europa occidental. 1280-1480, Pamplona, 2005, pp. 295-322. 
de la infantería debe ser considerado, en el contexto hispánico, con muchos matices, dado que remite a formas de combate en campo abierto claramente evitadas en la década que nos ocupa. Esto no significa que los combatientes a pie ocuparan un papel marginal, antes al contrario, pero su importancia radicó, precisamente, en su funcionalidad poliorcética, sobre todo en el caso de los ballesteros. Y algo similar ocurre con las todavía muy rudimentarias armas de fuego. La introducción de la pólvora en piezas de artillería fue concebida como un sistema de apoyo en la defensa de las principales plazas fortificadas y su uso como medio ofensivo fue, al menos en tierra, muy poco relevante ${ }^{13}$.

Antes de pasar al análisis de las diversas categorías de combatientes y su armamento, conviene subrayar un aspecto que nos parece fundamental para situar la guerra de los Dos Pedros en la Historia de la técnica militar: las formas de combate aplicadas durante este conflicto vinieron a prolongar las estrategias y los recursos propios de la guerra tradicional, desarrollada en la Península Ibérica durante las grandes fases de la expansión feudal, en los siglos XII y XIII. En este sentido, la estrategia predominante consistía en lanzar cabalgadas, es decir, ataques esporádicos sobre el territorio enemigo, concebidos con el fin de capturar botín, cautivos o, sencillamente, destruir los bienes del contrario. Esta forma de hacer la guerra se había generalizado en los territorios de frontera entre los reinos feudales y al-Andalus, donde la discontinua sucesión de enfrentamientos, en contextos diplomáticos siempre inestables, provocaron una secular situación de guerra de baja intensidad ${ }^{14}$. El éxito de estas acciones dependía directamente del nivel de coordinación existente entre las tropas de caballería y las populosas compañías de peones encargadas de asegurar el control de las fortalezas.

\section{CATEGORÍAS DE COMBATIENTES EN LAS COMPAÑÍAS ARAGONESAS}

\subsection{Los hombres a caballo: armados y aforrados}

El núcleo de los ejércitos a mediados del siglo XIV estaba constituido todavía por las tropas de caballería. Según sus características técnicas, en el Aragón bajomedieval estas tropas se diferenciaban en dos tipos de unidades: los caballos armados y los aforrados. Los primeros se corresponden con el equipo de guerra propio de la caballería pesada, compuesto por una montura de potencia notable preparada como fuerza de choque. Los hombres a caballo aforrados, por su parte, estaban dotados de un equipamiento menor. Sus monturas, generalmente, eran de un nivel inferior a las de las tropas de caballería pesada y sus arneses eran mucho menos complejos. La cantidad total de combatientes a caballo documentados en Aragón, incluidos los

\footnotetext{
13 Algunos tipos de barcos de guerra sí llegaron a montar artillería de fuego. Véase al respecto Manuel Sánchez Martínez, "Un episodio de la guerra de los Dos Pedros: la defensa costera de Cataluña en el verano de 1365", Poder y sociedad en la baja Edad Media. Estudios en Homenaje al profesor Luis Vicente Díaz Martín, Valladolid, 2002, pp. 273-288.

14 En palabras de Manuel Rojas, una cabalgada era "una operación militar cuyo propósito esencial no incluía ni la adquisición permanente de territorio enemigo ni ningún tipo de combate directo con el adversario, siendo su finalidad, única o combinada, y en el seno de una guerra de posición y de desgaste, desde la más pura depredación, saqueo y obtención de botín, hasta un medio de dañar la moral y capacidad de resistencia del contrario, pasando por la neta represalia a un golpe anterior, un ataque de distracción en un área fronteriza diferente a donde estaba teniendo lugar el grueso de una ofensiva, la manera de asegurarse pertrechos adecuados durante una campaña o expedición, una forma de presión para alcanzar algún tipo de acuerdo, un cauce para obtener información o un acto simbólico de fuerza." Manuel Rojas Gabriel, "El valor bélico de la cabalgada en la frontera con Granada (c. 1350-1481)", Anuario de Estudios Medievales, 31, (2001), pp. 295 328, cita en p. 309. Véase también Francisco García Fitz, "La didáctica militar en la literatura castellana (segunda mitad del siglo XIII y primera del XIV)", Anuario de Estudios Medievales, 19, 1989, pp. 271-284; y Pedro A. Porras Arboledas, "El Derecho de frontera durante la Baja Edad Media. La regulación de las relaciones fronterizas en tiempo de treguas y de guerra", Estudios dedicados a la memoria del Profesor L.M. Díez de Salazar, Bilbao, 1992, t. I, pp. 261-287.
} 
dos tipos citados, durante la guerra de los Dos Pedros, se situó en un mínimo de 1.757 hombres a finales de 1356 y un máximo de 4.105 en el primer semestre de 1357. La dinámica general apunta, no obstante, a una provisión de algo menos de 3.000 unidades de caballería durante la mayor parte del conflicto ${ }^{15}$.

La relación entre las dos categorías de monturas se mantuvo generalmente en torno a los dos tercios de caballería pesada y uno de ligera, o al menos esta fue la distribución empleada a efectos económicos. En este sentido, no podemos olvidar que las denominaciones armado y aforrado funcionaban, en no pocas ocasiones, como simples unidades de cuenta, de manera que lo designado no era una realidad material concreta, sino el coste de los salarios de cada compañía y por lo tanto, la cantidad que debía recibir su titular, con independencia de las cualidades concretas de sus integrantes. Dichos salarios se fijaron, a partir de 1357, en 7 sueldos diarios por caballo armado y 5 por aforrado, aunque la disponibilidad de recursos, las necesidades militares y las características propias de ciertos combatientes terminaron por alterar dichas asignaciones ${ }^{16}$. Sirva de ejemplo la diferente tasación empleada al comienzo de la guerra con respecto a las tropas de los aliados castellanos del rey de Aragón: Enrique de Trastámara, Álvaro García y Gómez Carrillo. Los tres iban a recibir 8 sueldos barceloneses diarios por cada uno de sus hombres a caballo armados y 6 sb por sus hombres a caballo con arco y también por sus tropas de caballería ligera ${ }^{17}$. Asimismo, las monturas de combate pertrechadas con animales dedicados normalmente al trabajo, principalmente mulas, se equipararon a los caballos aforrados aunque recibieron un salario inferior, normalmente fijado en torno a los 4 sueldos diarios ${ }^{18}$.

Tanto los hombres a caballo armados como los aforrados aglutinaban en torno a sí mismos a un número variable de efectivos y de monturas cuya cuantificación exacta, para determinados contextos, supone un verdadero problema. La determinación del número de personas y caballerías que implicaba cada tipo de combatiente ha podido ser resuelta, por el momento, para contextos próximos a la guerra de los Dos Pedros, pero no para este caso concreto. Seguramente, la referencia a esta cuestión mejor conocida por los historiadores es la contenida en el legajo 416 de la sección Varia de Cancillería, en el Archivo de la Corona de Aragón. En dicho documento, se recogen con cierto detalle los preparativos de la expedición a Cerdeña que, en 1323, dirigió el infante Alfonso. En la memoria de objetos necesarios para dotar a la armada, se lee:

«Item, han mester XII mille homens d'armes, es a saber M cavaylls armats, que a raho de $\mathrm{V}$ homens per cascun cavayll fan V mille. E II mille ballesters e III mille soudats e C homens a cavayll a la geneta, qui seran ab los homens de peu tro a CCC. E axi seran per tots altres aquells damunt dits del armament de les galees X mille CCC; mas per be bastar es fet compte a XI mille homens ${ }^{19}$ ».

15 Mario Lafuente Gómez, Un reino en armas. La guerra de los Dos Pedros en Aragón (1356-1366), Institución Fernando el Católico, Zaragoza, 2013, pp. 90-92.

16 ACRA II, p. 201.

17 ACA, R.Pat., M.Rac., 894 (albaranes de julio de 1356 a mayo de 1357).

18 Así se refleja en las cuentas de los pagos por hombres a caballo desde julio de 1356, ACA, R.Pat., M.Rac., 894.

19 ACA, Canc., Varia, 416, f. 10. Publicado por Antonio Arribas Palau, La conquista de Cerdeña por Jaime II de Aragón, Barcelona, 1952, doc. XIX. Lo emplean también Manuel Sánchez Martínez, "Guerra, avituallamiento del ejército y carestías en la Corona de Aragón”, Historia. Instituciones. Documentos, 20 (1993), pp. 523-549; y María Teresa Ferrer i Mallol, "La organización militar en Cataluña en la Edad Media", Conquistar y defender. Los recursos militares en le Edad Media Hispánica, ed. M. A. Ladero Quesada, Madrid, 2001, pp. 119-222, concretamente p. 169. 
Según esta fuente, en el contexto de la citada expedición, un caballo armado agrupaba a cinco personas, es decir, a cuatro hombres además del cabalgador. No queda claro, sin embargo, cuántas caballerías había junto a la montura principal. El texto indica explícitamente que fueron contabilizados cinco hombres por cada caballo armado, sin indicar que se dispusiera de otros animales, pero es difícil pensar que estas compañías no contaran con monturas secundarias. Sí se anota claramente, en cambio, que cada una de las monturas de caballería ligera, a la geneta, implicaban además a dos hombres a pie, haciendo un total de tres hombres y un caballo por unidad. Por otro lado, la disponibilidad de más de una caballería por parte de los hombres a caballo armados ha sido constatada en documentación similar, por ejemplo, en la generada durante la expedición a Almería planeada por Alfonso IV en 1329. Para esta ofensiva, se ha documentado un mínimo de dos cabalgaduras por unidad de caballo armado $^{20}$. No obstante, antes de trasladar cualquiera de estos datos al ámbito que nos ocupa es preciso actuar con prudencia, ya que en ambos casos se trata de acciones ofensivas y, por lo tanto, propicias para una mejor dotación del ejército.

Con casi total seguridad, los ejércitos de Pedro IV en la guerra de los Dos Pedros conocieron una relación entre unidades de caballería y elementos agregados bastante más sencilla. Un indicio de ello está documentado para Cataluña, ya que las Cortes de Perpiñán de 1356 cuantificaron los elementos que componían la unidad del caballo armado en su cabalgador, un escudero y dos hombres a pie, es decir, en cuatro personas, sin que quede claro si el citado escudero disponía también de una montura ${ }^{21}$. Algunos años más tarde, ya en plena guerra civil castellana, las Cortes aragonesas reunidas en Zaragoza, en 1367, sancionaron la obligación de mantener una acémila por cada dos hombres a caballo, prescindiendo de cualquier otra montura ${ }^{22}$.

Por otra parte, los efectivos de caballería pesada que, procedentes de fuera de la Corona de Aragón, se pusieron al servicio de Pedro IV fueron equiparados, a efectos económicos, a los hombres a caballo armados. Se trata de los glavis franceses, cuyos salarios fueron tasados en 7 sueldos barceloneses diarios. Los primeros combatientes de este tipo estuvieron liderados por Darot de Forestay, procedente de Aviñón, quien tuvo a su cargo a once glavis en abril y mayo de $1357^{23}$. También en aquellos momentos se encontraba al servicio de Pedro IV Gastón, conde de Foix, con un importante número de combatientes, entre ellos varios cientos de glavis de origen francés. El número total de unidades de este tipo que pudo proporcionar, a finales de mayo de 1357, alcanzó las $850^{24}$. La denominación glavis para referirse a las tropas de caballería pe-

20 Entre los datos proporcionados por Manuel Sánchez, se anota que en la expedición se incluyeron 1.000 caballos armados y 500 aforrados, mientras que la cantidad total de monturas era de 3.250. M. Sánchez Martínez, “Guerra, avituallamiento", cit., p. 545.

$21 M^{\mathrm{a}}$ T. Ferrer i Mallol, "La organización militar en Cataluña", cit., p. 169

22 "Que los ditos hombres a cavallo pues convenient sueldo se les da sian tenidos de haver sus açemblas proprias, yes asaber, entre dos cavallos una acembla, et si mas mester end havian por la necessidat de la guerra, que les sian dados por los judges locales o jurados toda hora que requeridos end seran con el salario iuxta el scillo de la Cort del senyor rey et aquellas sian extimadas et dadas fianças por las extimas et logueros et qualquiere de los hombres a cavallo que por si o por otri si no en la forma sobredita azemblas pendran que haya perdido et pierda el sueldo de un mes et sia tenido pagar la extima et el loguero et que los ditos officiales sian tenidos dar las ditas acemblas en la forma sobredita cada que requeridos seran, et que firma de dreyto non sia recebida al noble cavallero ni al scudero ni a otro alguno por razon de las ditas azemblas et loguero. E si pora ventura si sin culpa de qui la levara la azembla el azemblero se ira con aquella que le sia demandada por furto et la pierda e sia aplicada al General et esto a conoscimiento de los diputados et quel senyor rey non ende pueda fer remission." ACRA III, pp. 263-264. En este proceso, también se establecieron las condiciones sobre la disponibilidad de acémilas ante una hipotética entrada en Castilla. Ibidem, p. 271.

23 Por 42 días de servicio (27 entre el 5 de abril y el 16 de mayo, más los 15 días en que se estimó la duración de su regreso a Francia), debía recibir 3.234 sb. ACA, R.Pat., M.Rac., 894, f. 67v (1357, may., 16. Zaragoza).

24 ACA, R. Pat., M.Rac., 887, ff. 136-137 (1357, may., 20. Zaragoza) y 140 (1357, may., 18. Zaragoza). 
sada está menos documentada en la segunda fase de la guerra. No obstante, tras la reanudación del conflicto en 1362, Pedro IV intentó seguir contando con estos efectivos, por ejemplo, con los cincuenta o sesenta glavis que podía proporcionarle el señor de La Esparra ${ }^{25}$.

Dentro de la evolución histórica de la caballería como medio de combate, los modelos empleados durante la guerra de los Dos Pedros suponen el final de las categorías tradicionales, que se iban a ver suplantadas, a mediados del siglo XIV, por un sistema basado en células de combatientes cuantificados como una única unidad. Este sistema se adoptó en Aragón por influencia francesa, de modo que, desde finales de la década de 1360 las unidades de caballería pesada comenzaron a ser denominadas lanzas. Sin duda, el cambio de nombre se debió a un cambio en los elementos propios del caballo armado, dirigido a perfeccionar su capacidad de combate. Para ello, se tomaron como referencia a las unidades de los ejércitos del rey de Francia, que exigían a un número de personas y caballerías mayor que el de los caballos armados. Prueba de ello es que en las Cortes de Caspe, Alcañiz y Zaragoza, celebradas entre 1371 y 1372, se habla ya de compañías armadas a la guisa nueva, según se hacía en los territorios más próximos a los dominios del rey de Aragón ${ }^{26}$. Estas modificaciones tuvieron, lógicamente, sus consecuencias económicas, ya que, en 1374, el salario de una lanza se tasó en 9 sueldos diarios, dos más que el de los antiguos caballos $\operatorname{armados}^{27}$. En las cortes aragonesas de Tamarite de Litera, del año 1375, el sueldo diario de las quinientas lanzas levantadas en defensa del reino ascendía ya a 1 florín (en torno a 10 sueldos jaqueses $)^{28}$. Su dotación consistía en dos caballerías, una para el combatiente y otra para su mozo o paje, según se explica en el primero de los capítulos derivados de la concesión:

«Los sobreditos prelados, nobles, cavalleros et procuradores de las ciudades, villas et lugares ordenaron por servicio del senyor rey et deffension del dito regno, et fazen ordinacion et provision que en el dito Regno de Aragon sian cincientas lanças armadas a la manera francesa, yes a saber cada una lança con dos cabalgaduras; la una buen rocin o buen cosser d'armas et sufficient; et la otra para el moço o page que lieve el glavi et el bacinet ${ }^{29} . »$

El cambio en la composición de las unidades de caballería pesada experimentado a finales de la década de 1360, así como la cuantificación de su coste en torno a 9 sueldos diarios, terminaron por consolidarse y constituyeron dos de los rasgos esenciales de los ejércitos de la monarquía aragonesa hasta finales de la Edad Media. En efecto, más de cien años después, las Cortes de Tarazona de 1495 concedieron a Fernando II un servicio destinado a sufragar el coste de 500 hombres a caballo, de los cuales, doscientos eran identificados como lanzas y debían recibir un salario de 10 sueldos jaqueses diarios ${ }^{30}$.

25 Para pagar su salario, se tomó como referencia a las tropas del conde de Foix, que habían recibido los 7 sueldos diarios. ACA, Canc., reg. 1183, ff. 90v-91 (1362, sep., 10. Barcelona).

26 "El [el rey] havia fecho clamar las ditas Cortes et plegar en el dito lugar por excitar et esveylar a ellos que fuessen vigiles et expertos en armas a la guisa nueva armados, segunt las otras gentes comarcantes a sus regnos et tierras agora nuevament se armavan.” ACRA III, pp. 289 y 340.

$27 \mathrm{M}^{\mathrm{a}}$ T. Ferrer i Mallol, "La organización militar en Cataluña", cit., p. 170.

28 "'[El rey] les requiria, rogava et mandava que el sueldo el qual havia stado ordenado por las cincientas lanças que fueron ordenadas para deffension del dito regno, el qual se pagava et se havia pagado a un florin por lança por cada un dia, por razon que las fronteras del dito regno et las companyas que stavan de cavallo en aquellas fuessen proveydas et deffendidas, et que por otras gentes stranyas non pudiessen seyer invadidas, fuesse continuado siquiere prorrogado por aquel tiempo que a ellos fuesse bien visto." ACRA III, p. 514.

29 ACRA III, pp. 551-552.

30 A partir del séptimo mes, el salario se reducía hasta 8 sueldos y 4 dineros. La descripción de las lanzas figura en las actas del proceso: "Los dozientos havian de ser hombres de armas con sus pages y cavallos encubertados y todos armas blancas según pertenescia a hombres de armas". José Antonio Armillas Vicente y Enrique Solano Camón, "El servicio militar al rey en las Cortes de 1495", Aragón en la Edad Media, VIII (1989), pp. 71-86, especialmente p. 73. 
El segundo tipo de montura de combate se correspondía con la caballería ligera, que, en la Corona de Aragón, quedaba englobada dentro de la denominación genérica caballos aforrados. Este tipo de combatientes eran conocidos también como monturas a la jineta, denominación que denota una evidente influencia del mundo islámico y, más concretamente, del reino de Granada. De hecho, la mayoría de los efectivos documentados bajo esta denominación, en el ejército aragonés, eran granadinos, entre los que merece la pena citar a los nueve jinetes que, en marzo de 1357, dirigía un musulmán de nombre Alíi1; o la compañía de Alabes Benafrafim, cap de doce moros de la jineta, en julio de $1359^{32}$. Algunos cristianos figuraron también como hombres a la jineta y fueron tasados, al igual que los anteriores, como caballos aforrados. En proporción, debieron de ser muy pocos los efectivos que reunieron estas características, ya que únicamente hemos documentado a uno de ellos. Se trata de un vecino de Tarazona, Alfonso de Soria, quien a comienzos de 1363 montaba a la jineta un caballo de su propiedad ${ }^{33}$.

Frente a la evolución mostrada por las monturas de caballería pesada, todo apunta a que las tropas de caballos aforrados experimentaron muy pocos cambios a lo largo de la baja Edad Media. En efecto, el servicio otorgado en las Cortes de Tarazona de 1495, al que nos hemos referido anteriormente, fijaba el salario de las tropas de este tipo en la cantidad acostumbrada durante el tercer cuarto del siglo XIV, es decir, en 5 sueldos diarios ${ }^{34}$. No obstante, el criterio económico, como indicador de la evolución en la tipología de los combatientes a caballo, resulta útil siempre y cuando comparemos el mismo tipo de documentación, como sucede en este caso con los capítulos de los servicios pactados en Cortes. Nos parece relevante destacar este hecho, ya que en otro tipo de fuentes podemos encontrar tasaciones diversas condicionadas por criterios particulares. Por ejemplo, en la movilización de milicias municipales, dirigidas por la autoridad de los concejos, las cantidades de las soldadas dependían de la disponibilidad de recursos o de la voluntad de las propias oligarquías locales. Así, por ejemplo, en 1463, cuando en la sobrejuntería de Ejea se levantaron ciertos contingentes para combatir frente a Navarra, el sueldo de los hombres a caballo se fijó en 4 sj diarios. La pequeña compañía documentada en este contexto conoció una gran inestabilidad e incluyó un mínimo de doce y un máximo de veinte hombres a caballo, cuya tipología no llegó a ser expresada junto a la contabilidad de su administración ${ }^{35}$.

\subsection{Los peones: almogávares, fletxers, ballesteros o servents, lanceros y escudats}

Los contingentes de hombres a pie en los ejércitos bajomedievales fueron, generalmente, mucho más numerosos que las tropas a caballo. A pesar de que su importancia suele quedar relegada por el carisma y el prestigio de las fuerzas de caballería, la historiografía no ha dejado de destacar, en las últimas décadas, la enorme funcionalidad que los combatientes a pie tuvieron en la guerra medieval. Clifford J. Rogers, por ejemplo, sitúa la «revolución de la

31 ACA, R. Pat., M.Rac., 887, ff. 103-104 (1357, mar, 13. Calatayud).

32 Esos doce hombres eran: Suay de Benmassot, Alí Benzaguari, Maffomet Benali, Suayt Benaffia, Mansor Benfamo, Amir Benabraffim, Abrafim Benjaffia, Maffumet Ben Juceff, Massot Abenabdalill, Mansor de Bera, Abraffim de Granada y Abraffim Bensuayt. ACA, R.Pat., M.Rac., 889, f. 50 (1359, jul, 2. Barcelona). En marzo del año siguiente, la compañía de Alabes Benafrafim estaba integrada únicamente por siete hombres: Mansor de Bera, Idon Bonsayt, Mafumat bon Jucef, Masot (hijo de Adalill), Ali Bonsa Cari, Abrafim Bonafia y Mafumet bon Ali. Ibídem, f. 84 (1360, mar., 11. Tarazona).

33 ACA, R.Pat., M.Rac., 2498, ff. 34-34v (1363, feb. 8 y 12. Tarazona).

34 A partir del séptimo mes quedó sancionada incluso su rebaja hasta 4 sueldos 2 dineros jaqueses diarios, en paralelo al descenso que debían sufrir también los salarios de las lanzas. La descripción de estos combatientes, según las actas de la asamblea, es la siguiente: "Los trezientos a la gineta segun acostumbravan armarse, a saber es con coraças, capacetes, vavera, armaduras de braço, faldas y cuxotes”. J.A. Armillas Vicente y E. Solano Camón, "El servicio militar”, cit., p. 73.

35 Miguel Ángel Pallarés Jiménez, "Conto de los caballeros del sueldo, hombres de a pie y espías. Gastos de guerra del año 1463 en Cinco Villas”, Suessetania, 15-16 (1996-1997), pp. 124-136, especialmente pp. 127-128. 
infantería» en una fecha tan temprana como la batalla de Courtrai, en 1302. La consecuencia más relevante de este fenómeno, según el citado autor, era la inclusión de la función militar entre la población no aristocrática, con un peso específico considerable y de forma sostenida en el tiempo, influyendo así en la concepción misma de la guerra ${ }^{36}$. Independientemente de este hecho y, desde un punto de vista estrictamente técnico, no cabe duda de que muchas de las actividades desarrolladas en el combate dependían exclusivamente de los grupos de peones. Las características de la guerra de los Dos Pedros, desarrollada en torno a acciones de desgaste $\mathrm{y}$ asedio, hicieron que algunos de estos contingentes tuvieran un papel fundamental en el reino de Aragón, especialmente en lo que respecta a las guarniciones encargadas de defender las fortificaciones. Sin embargo, todos ellos fueron utilizados también en operaciones concretas de ataque e incluso en algunas internadas en territorio castellano ${ }^{37}$.

En este sentido, los grupos de almogávares fueron sin duda quienes intervinieron en un mayor número de operaciones. Organizados prioritariamente en cuadrillas de pocos efectivos (entre cinco y quince hombres), los almogávares estaban especializados en acciones puntuales de saqueo en las que intervenían bien como apoyo de un grupo de hombres a caballo, o bien disponiendo por ellos mismos de algunas monturas. Las fuentes, cuando los citan, únicamente proporcionan el nombre de su líder o adalid, única forma de acceder al origen social de estas compañías $^{38}$. El potencial conjunto de estas pequeñas compañías no debe ser menospreciado, ya que, en octubre de 1363, por ejemplo, eran nada menos que 150 almogávares los que, organizados en grupos menores, debían combatir en el entorno de Daroca ${ }^{39}$.

El resto de combatientes a pie solían recibir apelativos derivados de un tipo de armamento determinado, si bien el grado de especialización en su manejo podía ser diverso. Uno de los grupos mejor dotados en este sentido eran los arqueros o fletxers, de origen francés, castellano o navarro y todavía no muy numerosos en comparación con otros territorios europeos ${ }^{40}$. Algunos de los mayores contingentes de este tipo fueron proporcionados por Gastón, conde de Foix, en la primera fase de la guerra. En la primavera de 1357 tuvo, al menos, a veintinueve de estos arqueros al servicio de Pedro $\mathrm{IV}^{41}$. Al intentar incorporar al señor de La Esparra en septiembre de 1362, junto a los cincuenta o sesenta glavis a los que ya nos hemos referido, Pedro IV solicitó también algunos fletxers como los aportados anteriormente por el conde de Foix. Su salario, en ambos casos, se tasó en 4 sueldos diarios, una cantidad notable en comparación con los otros peones, quienes iban a recibir 1 sueldo y 8 dineros al día ${ }^{42}$. Su coste denota, sin duda, un grado de especialización propio de un cuerpo de élite. Otro fletxer, Erberant de la

36 Clifford J. Rogers, "The Military Revolutions”, cit., pp. 58-64; y, del mismo autor, "La época de la Guerra de los Cien Años", en Historia de la guerra en la Edad Media, ed. M. Keen, Antonio Machado Libros, Madrid, 2005 ( $1^{\text {a }}$ ed. 1999), pp. 179-208, concretamente p. 187. Para finales de la Edad Media e inicios de la época moderna, la importancia de la infantería ha sido destacada, entre otros, por Luis Ribot García, "Types of Armies: Early Modern Spain”, War and competition between states, ed. Philippe Contamine, Oxford, 2000, pp. 37-68.

37 Laurence W. Marvin ha utilizado el apelativo "aquellos que trabajan" (those who work) para referirse a los cuerpos de lanceros, arqueros, ballesteros, piqueros, etc. involucrados en la práctica del combate. Lawrence W. Marvin, “'... Men famous in combat and battle...': Common Soldiers and the siege of Bruges, 1127', Journal of Medieval History, 24 (1998), 3, pp. 243-258.

38 Por ejemplo, la del aragonés Lope Sánchez de Rueda, ACA, Canc., reg. 1193, f. 73v (1364, feb, 19. Uncastillo); o la del castellano Domingo Andrés, al servicio de Enrique de Trastámara, ACA, Canc., reg. 1196, f. 1v (1364, feb., 19. Uncastillo).

39 La autoridad encargada de gobernarlos era el entonces capitán de Daroca, fray Pedro Muñiz de Godoy, maestre de Calatrava. ACA, Canc., reg. 1191, ff. 549-549v (1363, oct., 6. Barbastro).

40 Además de la denominación fletxers, las fuentes aluden a ellos como flatxes y fletxes.

41 ACA, R.Pat., M.Rac., 887, f. 115 (1357, abr, 22. Calatayud). Esta referencia recoge un pago por un grupo fletxers de número indeterminado, que ascendió a $50.000 \mathrm{sb}$. En otro de los documentos, al cual hemos remitido al hablar de sus 850 glavis, se indica que el número de fletxers de que disponía era veintinueve. Ibídem, f. 140 (1357, may, 18. Zaragoza).

42 ACA, Canc., reg. 1183, ff. 90v-91 (1362, sep, 10. Barcelona). 
Maya, formó parte del ejército aragonés también al comienzo de la guerra de los Dos Pedros, junto a un único compañero. Su salario se corresponde con el recibido por los anteriores, es decir, 4 sueldos barceloneses diarios ${ }^{43}$. Siguiendo la tipología establecida por Robert J. Bartlett, estaríamos hablando de pequeños grupos de especialistas en el manejo de arcos de un tamaño mayor a los usados en otros territorios europeos, como los escandinavos o los magiares ${ }^{44}$. Dado su origen y la cronología en que están localizados, se trataría seguramente de hombres con experiencia adquirida al comienzo de la guerra de los Cien Años, quizás propietarios de longbows al estilo inglés ${ }^{45}$.

Entre las tropas de Enrique de Trastámara, ya desde el comienzo de la guerra, se contabilizaron también algunos de estos efectivos, con la particularidad de que una parte de ellos combatía a caballo. Su origen, sin embargo, era francés y se incorporaron a los ejércitos de Pedro IV como consecuencia de la estancia del conde en Francia. Este tipo de efectivos se corresponde, muy probablemente, con el tipo de arqueros a caballo surgido en la década de 1330 en Inglaterra, cuya finalidad principal era la protección de las tropas de peones. Eduardo III promovió la formación de estos combatientes, de modo que durante las primeras fases de la guerra de los Cien Años su actividad fue decisiva. Pero el hecho de poseer un caballo no significa que combatieran montados. Como ha subrayado A. Ayton, los arqueros ingleses desmontaban antes de disparar, ya que el uso del arco al galope era una modalidad propia de los ejércitos orientales e islámicos prácticamente indocumentada en Europa ${ }^{46}$. Su nula presencia entre las fuerzas originarias de la Corona de Aragón se debe, probablemente, a su escasa rentabilidad en comparación con el resto de las tropas.

El primer grupo de fletxers incluido entre las compañías del conde de Trastámara estaba compuesto por 24 unidades, que llegaron a Aragón procedentes de Poitiers y estuvieron a sus órdenes entre octubre y diciembre de $1356^{47}$. De ellos, una mitad eran hombres a pie, que recibieron $4 \mathrm{sb}$ diarios, mientras que la otra mitad, a caballo, cobraron $6^{48}$. Este grupo se redujo a 16 integrantes a partir del 21 de diciembre de dicho año ${ }^{49}$. Juan Ramírez de Arellano también contó con algunos de estos combatientes entre sus efectivos. Sin embargo, la denominación fletxer, en este caso, hace referencia a un tipo de combatiente provisto de un arco distinto a los anteriores, ya que los salarios documentados son muy inferiores a los que acabamos de

43 Por 56 días de servicio, entre el 1 de abril y el 26 de mayo de 1357, ambos recibieron 448 sb. ACA, R.Pat., M.Rac., 894, f.95 (1357, may, 26. Zaragoza).

44 Robert J. Bartlett, "Technique militaire et pouvoir politique, 900-1300”, Annales ESC, 41, no 5 (1986), pp. 1135 1160, concretamente p. 1.138 .

45 Michael Prestwich, "El desafío de la caballería: el arco y la pica", La guerra en la Edad Media, ed. Matthew Bennet, Akal, Madrid, 2010 (ed. or. 2009), pp. 160-181; Martin J. Dougherty, Armas y técnicas bélicas de los caballeros medievales. 1000-1500, Libsa, Madrid, 2010, pp 16-91; Matthew Bennet, Jim Bradbury, Kelly De Vries, Iain Dickie y Phyllis G. Jestice, Técnicas bélicas del mundo medieval. 500-1500 d.C. Equipamiento, técnicas y tácticas de combate, Libsa, Madrid, 2007, pp. 67-130.

46 Andrew Ayton, "Armas, armaduras y caballos", Historia de la guerra en la Edad Media, ed. M. Keen, Antonio Machado Libros, Madrid, 2005 ( $1^{\text {a }}$ ed. 1999), pp. 239-267, concretamente pp. 249-251.

47 La primera referencia en ACA, R.Pat., M.Rac., 887, f. 30 (1356, dic, 8. Calatayud). En Navarra está documentada también la presencia de estos arqueros a caballo. La primera referencia corresponde a Robert el Inglés, en 1362. J.A. Fernández De Larrea Rojas, "Cambios en el sistema militar navarro en la segunda mitad del siglo XIV", Príncipe de Viana, Anejo 8. Primer Congreso General de historia de Navarra, Pamplona, 1988, t. 3, pp. 413-423, concretamente p. 414. Sus salarios, en este caso, ascendían al 50 o $60 \%$ del recibido por un hombre de armas, proporción similar a la comprobada para la compañía del conde de Trastámara, que se situaba en torno al 50\%.

48 El servicio de todos ellos está documentado entre el 14 de octubre y el 20 de diciembre de 1356, haciendo un total de 67 días. Por ello, los doce hombres a caballo recibieron $4.824 \mathrm{sb}$ (a $6 \mathrm{sb}$ diarios cada uno) y los doce a pie 188 florines de oro y $18 \mathrm{db}$ (a $7 \mathrm{fl}$ or mensuales por cada uno de ellos). ACA, R.Pat., M.Rac., 894, ff. 50-50v (1357, ene., 22. Zaragoza).

49 La cantidad total recibida por los dieciséis ascendió a $115 \mathrm{fl}$ or y 9 sb. ACA, R.Pat., M.Rac., 894, ff. 53-53v (1357, ene., 29. Zaragoza). 
mencionar. Concretamente, se trata de dos grupos de combatientes a los que se alude como escalers e fletxers. El primero de ellos contaba con 47 miembros, mientras que el segundo estaba compuesto por 60 integrantes. Ambos están documentados en marzo de 1361 y recibieron 15 dineros barceloneses por persona y día ${ }^{50}$.

De todos los efectivos a pie, sin duda los más numerosos, tanto en los ejércitos aragoneses como en los castellanos, fueron los ballesteros, que en la Corona de Aragón se conocían también como servents ${ }^{51}$. El uso de la ballesta se había generalizado en Europa desde el siglo XII, llegando a constituir el elemento más característico de las milicias concejiles. Este hecho se debe, sobre todo, a su eficiencia, ya que la ballesta era un arma extraordinariamente funcional — tanto para el combate como para la caza - y relativamente asequible económicamente. Por ello, su utilización en caso de sitio era un recurso de gran eficacia, de modo que las guarniciones de los castillos solían estar especializadas en su manejo ${ }^{52}$.

Los grupos de ballesteros o servents solían ser bastante numerosos, llegando a alcanzar entre treinta y cincuenta efectivos bajo el mando de un conestable o cap. Teniendo en cuenta el salario asignado, podían llegar a ser los combatientes mejor pagados entre aquellos reclutados por los concejos como tropas a pie, ya que varias de las referencias localizadas al respecto indican que habían de cobrar 2 sueldos diarios ${ }^{53}$. Este tipo de combatiente se corresponde con el perfil de las compañías reclutadas por las universidades, como se observa en las diversas convocatorias emitidas desde la cancillería regia, para dotar tanto las villas y ciudades como las fortificaciones. En marzo de 1363, por ejemplo, el rey encomendó a Jaume Dez Prats el reclutamiento de doscientos ballesteros en los lugares de las órdenes de Calatrava y del Hospital, que serían destinados a Daroca, con un salario de dos sueldos jaqueses diarios para cada uno de ellos ${ }^{54}$. En abril de 1361, desarrolló una función similar Lope de Gurrea, quien envió a dos escuderos por orden del rey a Jaca, Barbastro y Aínsa para acordar ballesteros. Mediante pregones, varios corredores publicaron que recibirían salario quienes supieran tirar con ballesta y decidieran aceptar la convocatoria ${ }^{55}$.

En ocasiones, el número de peones que servían junto a los hombres a caballo podía alcanzar cifras notables, como en el caso de la compañía de doscientos peones (cien ballesteros y cien lanceros) que acompañaban a los hombres a caballo del arzobispo de Zaragoza a finales

50 El primer grupo fue registrado entre el 14 y el 20 de marzo (7 días), haciendo un total de $411 \mathrm{~s} 3 \mathrm{db}$; el segundo, entre el 21 de marzo y el 30 de abril (40 días), supuso un coste de 3.000 sb. ACA, R.Pat., M.Rac., 895, ff. 10v-11 (1361, abr., 24. Calatayud).

51 Al menos desde la preparación de la expedición a Cerdeña de 1323 ambas palabras son utilizadas como sinónimos. ACA, Canc., Varia, 416, ff. 26-33v. El cuaderno consta de dos fragmentos, de 17 y 39 folios respectivamente. En el segundo de ellos, en los folios 26-33v, se enumeran los ballesteros reclutados en Cataluña (28-30v), en Valencia (31-32v) y en Aragón (33-33v).

52 Mario Orsi Lázaro, "Estrategia, operaciones y logística en un conflicto mediterráneo. La revuelta del juez de Arborea y la armada e viatge de Pedro el Ceremonioso a Cerdeña (1353-1354)", Anuario de Estudios Medievales, 38/2 (jul.-dic. 2008), pp. 921-968, especialmente pp. 947-952.

53 Así se lo recordaba Pedro IV al juez de Teruel en la primavera de 1357, apremiándole a que fuesen pagados aquellos ballesteros que había proporcionado la ciudad: "A los quales [peones] por los cabos de cinquantenas se pago el sueldo o stipendio, es a saber al ballastero dos sueldos e al lancero XVIII dineros por cada un dia. Ond como del dito sueldo o stipendio reste a pagar a los ditos peones por cierto tiempo, e sea de razon que pues en nuestro servicio e por deffension del regno e utilidat de la cosa publica, son seydos e han sustenido danyos e menoscabos, qu'el dito sueldo les sia pagado". ACA, Canc, reg. 1157, f. 13 (1357, may., 12. Magallón).

54 ACA, Canc., reg. 1384, ff. 180-180v (1363, mar, 4. Monzón). Hay constancia de una compañía de 199 ballesteros que, procedentes de Tortosa y sus inmediaciones, hicieron muestra en Zaragoza en septiembre de 1364, junto a otras compañías de hombres a caballo naturales de Cataluña y Valencia. ACA, R.Pat., M.Rac., 2497, ff. 32-33v (1364, sep., 22. Zaragoza).

55 ACA, R.Pat., M.Rac., 889, f. 119v (1361, abr., 27. Calatayud). 
de $1356^{56}$; o los 470 servents que tenía bajo su mando Enrique de Trastámara en ese mismo momento $^{57}$. El conde, además, disponía de un contingente de doscientos servents de guardar sou cors que permanecieron junto a él al menos entre enero y mayo de $1357^{58}$. La precisión en esta última referencia permite pensar en una función protectora desarrollada por estos ballesteros, no sólo sobre la persona del conde, sino también sobre sus compañeros a caballo. El hecho de contar con un cuerpo de tiradores que, en un momento de necesidad, permitiese mantener alejados a posibles atacantes está documentado también para la compañía del propio rey. En mayo de 1361, por ejemplo, Romero de Bordalba tenía a su cargo, como cap, a sesenta servents ordenados por el rey para escoltar (hacer las scoltes) a su propia hueste ${ }^{59}$. Asimismo, conocemos la aplicación de esta medida a una escala menor. Cuando, a comienzos de 1361, Antón de Altabás, se dirigió desde Tarazona a Vozmediano y Trasmoz, para hablar con sus respectivos alcaides, lo hizo acompañado de cinco hombres a caballo y quince ballesteros ${ }^{60}$.

Por otro lado, la adaptación de los ballesteros o servents a la defensa de las fortificaciones es un hecho ampliamente constatado para la baja Edad Media y, de hecho, algunos autores han hablado de una notable superioridad táctica por parte de los defensores de las plazas fuertes, al menos hasta la generalización de armas de fuego de cierta potencia, ya en la segunda década del siglo $\mathrm{XV}^{61}$. En cada uno de los castillos situados en el límite del reino podemos apreciar a grandes rasgos este modelo. Sirva de ejemplo la Torre de Martín González, en el entorno del río Jalón. De dimensiones reducidas, su defensa se basó a lo largo de todo el conflicto en la dotación de ballesteros. Los grupos alojados en la Torre fueron relativamente pequeños, ya que reunieron entre treinta y sesenta hombres, pero fundamentales para resistir los asaltos castellanos, al igual que en muchos otros puntos de las proximidades, como Embid de Ariza, Bordalba, Monreal, Berdejo o Bijuesca. Entre finales de 1356 y los momentos inmediatamente anteriores a la paz de Tudela, firmada a mediados del año siguiente, en la Torre de Martín González permanecieron únicamente treinta servents, comandados por Pedro Garcés de la Torre ${ }^{62}$. Nos parece oportuno subrayar este hecho si tenemos en cuenta que, en dicho periodo, las incursiones castellanas por el valle del Jalón fueron habituales, produciéndose de forma paralela a la gran ofensiva que en la zona del Moncayo terminó por conquistar Tarazona.

Por último, existieron otros dos tipos de combatientes a pie: los lanceros, y los pavesados o escudats. En ambos casos disponemos de muy pocas referencias, algunas de ellas ya citadas al hablar de los ballesteros. Los lanceros, como su propio nombre indica, estaban equipados con una lanza o azagaya y recibían un salario sensiblemente inferior al de los ballesteros. En casos excepcionales, cuando se indicaba el salario de 2 sueldos diarios para los ballesteros, se

56 Entre el 5 de noviembre y el 4 de diciembre. La compañía de hombres a caballo del arzobispo era entonces de 118 unidades, comandadas por Pedro Martínez de Arbea y Jimeno López de Embún. Por los treinta días de servicio, más otros cinco para regresar a sus hogares, recibieron un total de $8.750 \mathrm{sb}$, cantidad que se ajusta a un salario de 15 db al día por cada uno de los 200 peones. ACA, R.Pat., M.Rac., 894, ff. 6v-7 (1356, dic., 18. Daroca).

57 ACA, R.Pat., M.Rac., 887, f. 30 (1356, dic., 8. Calatayud).

58 Entre el 21 de enero y el 18 de mayo, junto a 890 hombres a caballo y otros 890 a pie no ballesteros. La cantidad recibida por los 118 días de servicio fue de 29.500 db, a 15 db diarios. ACA, R.Pat., M.Rac., 894, ff. 123-123v (1357, jun., 20. Zaragoza).

59 ACA, R.Pat., M.Rac., 889, f. 113v (1361, may., 3. Terrer).

60 Portaba dos cartas redactadas por Bernat de Cabrera. El viaje duró dos días y cobró por ello 40 sj. ACA, R.Pat., M.Rac., 891, ff. 15-15v (1361, ene., 30. Zaragoza).

61 Clifford J. Rogers, "La época de la Guerra de los Cien Años", Historia de la guerra en la Edad Media, ed. M. Keen, Antonio Machado Libros, Madrid, 2005 ( $1^{\text {a }}$ ed. 1999), pp. 179-208, concretamente p. 190; Francisco García FiTz, "Las guerras de cada día en la Castilla del siglo XIV", Edad Media. Revista de Historia, 8 (2007), pp. 145-181, especialmente pp. 166-172.

62 Por el período de tiempo entre el 15 de diciembre de 1356 y el 31 de mayo de 1357 (146 días) los 30 servents recibieron 6.570 sb, a $15 \mathrm{db}$ diarios cada uno. ACA, R.Pat., M.Rac., 894, ff. (1357, may., 12. Magallón). 
anotaba que los lanceros reclutados en las mismas condiciones habrían de recibir 18 dineros, cantidad nada despreciable si tenemos en cuenta que, en condiciones normales, un peón (ya fuese lancero o ballestero) recibía 15 sueldos al día ${ }^{63}$. Los escudats, según la profesora María Teresa Ferrer i Mallol, también iban equipados con algún tipo de arma ofensiva (lanza, azcona, dardo, etc.), si bien su elemento característico era el escudo, con el que debían proteger a los ballesteros mientras éstos cargaban sus armas ${ }^{64}$. Seguramente, muchos de los peones sobre los que no se especifican características concretas cumplieron esta función, ya que no hemos documentado a ningún escudat en las fuentes trabajadas. Sin embargo, sí hemos localizado un referencia directa a nueve escuderos de pie encargados de custodiar el castillo de Mesones, en el valle del río Isuela. Dichos escuderos eran de casa del arzobispo de Zaragoza y su salario, en marzo de 1361, era de 18 dj por persona y día ${ }^{65}$.

\section{TÉCNICAS E INSTRUMENTOS DE COMBATE}

Una vez que hemos definido los principales rasgos de las distintas categorías de combatientes integrados en las compañías aragonesas, en esta segunda parte del trabajo trataremos de ofrecer un análisis algo más específico sobre las técnicas y los instrumentos de combate. Este tema, por el momento, apenas ha interesado a los investigadores del Aragón medieval, a diferencia de lo ocurrido en otros territorios de la Corona, especialmente en Cataluña, cuyo máximo referente se encuentra en la obra de Martí de Riquer. Sin embargo, se encuentra lejos de nuestro ánimo la intención de actualizar la historiografía aragonesa en este aspecto. Más bien, los siguientes epígrafes deberían ser leídos como una introducción al tema, como un punto de partida para una línea de investigación que, tal vez, pueda proporcionar frutos mucho más jugosos en el futuro. Para ello, hemos diseñado un recorrido sobre los tres instrumentos básicos para el combate cuerpo a cuerpo: las monturas, el arnés del combatiente a caballo y la equipación de los peones. Además, hemos añadido también unas pequeñas notas sobre la introducción de piezas de artillería detonadas con pólvora en Aragón, que, en cierto modo, pueden considerarse como las primeras armas de fuego que se manejaron en el reino.

\subsection{El bien más preciado: una buena montura}

Uno de los fenómenos culturales más extendidos históricamente consiste en la interpretación de la naturaleza conforme a categorías y rasgos esencialmente humanos, es decir, la comprensión del mundo a través de su humanización. Este hecho significa, entre otras manifestaciones, la jerarquización de los astros, los elementos, las plantas y, sobre todo, los animales en correspondencia con los estratos existentes en cada sociedad, de modo que los niveles establecidos en el interior de los grupos humanos quedan proyectadas con fidelidad sobre

63 ACA, Canc, reg. 1157, f. 13 (1357, may., 12. Magallón). Hemos comprobado, anteriormente, que todos los peones solían recibir 15 sueldos diarios; por ejemplo, al hablar de la compañía de doscientos peones del arzobispo de Zaragoza, ACA, R.Pat., M.Rac., 894, ff. 6v-7 (1356, dic., 18. Daroca). En las cuentas de las milicias levantadas en la sobrejuntería de Ejea, en 1463, los salarios de los hombres a pie, sin más detalles, se fijaba todavía en 2 sj diarios, mientras que sólo superaban esta cifra los de algunos espías, que podían llegar a cobrar 4 sj al día. M.A. Pallarés Jiménez, "Conto de los caballeros del sueldo", cit., 128-129.

$64 \mathrm{M}^{\mathrm{a}}$ T. Ferrer i Mallol, "La organización militar en Cataluña", cit., p. 170.

65 Jahiel de Mesones, mudéjar de dicho lugar, recibió de fray Martín de Alpartil, comendador de Tobed y tesorero del arzobispo, los 175 s y 6 dj que sumaron los salarios de los nueve escuderos, por trece días de servicio. AHPrNtZ, Simón de Capiella, 1361, ff. 52-52v (1361, mar., 13. Zaragoza). 
el reino animal. El Occidente cristiano medieval desarrolló sus propias idealizaciones sobre estos aspectos a partir de varios precedentes históricos, especialmente la herencia de las civilizaciones del Próximo Oriente Antiguo y el mundo clásico, las culturas de raíz indoeuropea integradas tardíamente en el mundo romano y, desde el siglo VII en adelante, la civilización islámica. En todos estos ámbitos la riqueza de las creaciones culturales relacionadas, de uno u otro modo, con el mundo animal es desbordante, hasta el punto de que resulta complicado encontrar un aspecto de la realidad que, en algún momento o en algún lugar del pasado, no haya sido interpretado utilizando una alegoría de este tipo ${ }^{66}$. Las conexiones entre espacios y creencias, en este sentido, son inagotables, pero, sobre todas ellas, destaca muy especialmente un factor de continuidad: en todas las culturas, el caballo es el animal que atesora y, a la vez, dispensa de modo más patente el prestigio y la distinción ${ }^{67}$.

Según el escritor catalán del siglo XIII, Ramón Llull, el caballo había sido el animal elegido para ser el compañero del miles, es decir, el caballero, hombre escogido, a su vez, entre mil, debido sus elevadas cualidades morales. Las razones de tal elección se encuentran, precisamente, en la identificación entre las aptitudes del hombre y las del animal:

«Se buscó entre todas las bestias la más bella, la más veloz y capaz de soportar mayor trabajo, la más conveniente para servir al hombre. Y como el caballo es el animal más noble y más conveniente para servir al hombre, por eso fue escogido el caballo entre todos los animales y dado al hombre que fue escogido entre mil hombres; y por eso aquel hombre se llama caballero $\left.^{68}.\right\rangle$

Las palabras de Ramón Llull rivalizan en belleza con las recogidas en una antigua tradición árabe, según la cual, la creación del caballo por Dios habría sido posterior a la creación del propio ser humano. En la finalidad del creador, de nuevo, se encuentra el deseo de dotar al hombre de una compañía muy especial:

«Crearé para ti un ser que será la felicidad del bueno y la desgracia del perverso. La felicidad estará en su frente, la bondad en su lomo y la alegría en quien lo posea ${ }^{69} . »$

El pensamiento medieval está repleto de ejemplos de este tipo, la mayoría de ellos cargados de sensibilidad. Tales expresiones ponen de manifiesto, sin duda, la importancia adquirida por las monturas en la vida cotidiana y, en particular, en el ejercicio de la actividad militar propia de la aristocracia. Como hemos indicado anteriormente, a mediados del siglo XIV los combatientes a caballo eran todavía el núcleo de los ejércitos y formaban los contingentes mejor preparados y más solventes en los hechos de $\operatorname{armas}^{70}$. Dadas las características de la guerra de los

\footnotetext{
66 Michel Pastoureau, Una historia simbólica de la Edad Media occidental, Katz, Buenos Aires, 2006, pp. 27-88.

67 La bibliografía sobre el caballo como icono cultural es generosa, por lo que únicamente citaremos aquí algunos ejemplos. Para el mundo céltico: Irene Seco Serra y Jesús De La Villa Polo, "Fuentes literarias antiguas sobre los caballos en Hispania", El caballo en la antigua Iberia: estudio sobre los équidos en la Edad del Hierro, coord. M. Zamora Merchán y F. Quesada Sanz, UAM-RAH, Madrid, 2003, pp. 125-140; María del Mar Gabaldón Martínez, "El caballo en el mundo celta. Significado y simbolismo de los équidos entre los pueblos galos", Ibídem, pp. 219-240; Eduardo Sánchez Moreno, "El caballo entre los pueblos prerromanos de la meseta occidental", Studia Historica. Historia Antigua, 13-14 (1995-96), pp. 207-229. Para el mundo romano: Javier Arce, "Los caballos de Símmaco", Faventia: revista de Filología Clásica, no 4, f. 1 (1982), pp. 35-44; Gisela Ripoll López, "Panem et circenses. El circo y las carreras de caballos", Espacio, Tiempo y Forma. Serie I. Prehistoria y Arqueología, 3 (1990), pp. 305-320. Para el mundo árabe: Carlota Sánchez-Moliní Sáez, "El origen del caballo árabe", El saber en al-Andalus. Textos y estudios, I, eds. P. Cano Ávila e I. Garijo Galán, Sevilla, 1997, pp. 173-186.

68 Ramón Llull, Libro de la orden de caballería, ed. Luis Alberto de Cuenca, Alianza, Madrid, 1992, p. 28.

69 C. Sánchez-Moliní Sáez, "El origen del caballo árabe”, cit., p. 174.

70 A. Ayton, “Armas, armaduras y caballos”, cit, p. 263.
} 
Dos Pedros, su valor en ella no radicó en su capacidad de choque en campo abierto, sino en su movilidad y contundencia a la hora de efectuar cabalgadas, es decir, operaciones de saqueo directas sobre emplazamientos enemigos. En tales condiciones, el mantenimiento y la preparación de una buena montura de combate era una necesidad ineludible entre los miembros de los grupos más poderosos dentro de la estructura social, ya fuesen de origen nobiliario o ciudadano.

El uso militar del caballo llevaba aparejadas una serie de implicaciones económicas y sociales que comenzaban por la propia elección del animal ${ }^{71}$. Era preciso elegir una montura adecuada para el combate, suficientemente fuerte y resistente, corpulenta, bien dotada en sus extremidades y veloz. Un caballo de tales características suponía una inversión notable, tanto en el momento de su adquisición como, posteriormente, dado que su mantenimiento exigía una provisión de alimento adecuada y una serie de cuidados que incluían la asistencia de un albéitar y, generalmente, de uno o varios mozos encargados de limpiarlo y mantenerlo en for$\mathrm{ma}^{72}$. El entrenamiento de las monturas, de hecho, constituía una actividad imprescindible en la casa de sus propietarios y, en ocasiones, se realizaba a través de actividades concretas, como la caza, o sencillamente mediante el paseo regular.

Todos estos factores hicieron que, durante la Baja Edad Media, en los diferentes Estados europeos se desarrollaran sistemas de reembolso del valor de las monturas perdidas en combate. En la Corona de Aragón, la responsabilidad de efectuar el reintegro solía ser asumida por la monarquía y, de forma extraordinaria, por las Cortes de cada territorio, que podían asumir ocasionalmente el coste de las monturas perdidas. Así, el procedimiento comenzaba con la tasación del valor de los animales en las llamadas muestras o revistas de caballería, operación en la que participaban un oficial del rey, un escribano o un notario, y un delegado de las Cortes. Es difícil pensar que el sistema funcionase con precisión en todos los casos, lo cierto es que el valor de los caballos perdidos solía ser reintegrado bien por parte del monarca o bien por parte de los diputados designados por las Cortes $^{73}$. El valor económico medio de los caballos de combate empleados por las compañías que sirvieron en Aragón, durante la guerra de los Dos Pedros, osciló entre los 400 y los 800 sueldos jaqueses. Estas cantidades son sensiblemente inferiores a las documentadas para campañas anteriores, como la dirigida por el infante Alfonso para la conquista de Cerdeña, entre 1323 y 1325, o la encabezada por el propio Pedro IV contra esta isla, en 1354-1355 $5^{74}$.

\subsection{El arnés del combatiente a caballo: entre el pragmatismo y la distinción}

La fabricación de armas y arneses en la Edad Media, al igual que sucede con la mayoría de los bienes materiales, responde a unos criterios de funcionalidad, pero también a determinados factores de tipo cultural, dado que los objetos suelen proyectar categorías y valores específicos

71 Para todos estos aspectos, véase Mario Lafuente Gómez, "El uso militar del caballo y algunas de sus implicaciones económicas en Aragón durante el reinado de Pedro IV", Aragón en la Edad Media, XIX (2006), Homenaje a la profesora María Isabel Falcón Pérez, Universidad de Zaragoza, pp. 301-307.

72 B. Prévot y Bernard Ribémont, Le cheval en France au Moyen Age. Sa place dans le monde médiéval; sa médecine: l'exemple d'un traité vétérinaire du XIVe siècle, la "Cirurgie des chevaux", Paradigme, Orleans, 1994.

73 En los listados de agravios presentados en algunas asambleas, podemos encontrar reclamaciones de propietarios de caballos perdidos sin haber recibido reembolso alguno. Por ejemplo, en las sesiones de las Cortes celebradas entre $1365 \mathrm{y}$ 1367, ACRA III, pp. 1-276.

74 M. Lafuente Gómez, "El uso militar del caballo", cit., pp. 304-305; y, del mismo autor, Guerra en ultramar. La intervención aragonesa en el dominio de Cerdeña (1354-1355), Institución Fernando el Católico, Diputación Provincial de Zaragoza, Zaragoza, 2011, pp. 200-205. 
propios de quienes los manejan o los poseen ${ }^{75}$. Probablemente, ninguna de las armas, arneses u otros útiles cualesquiera de los empleados por los combatientes del Medievo ha cumplido esta función con mayor eficacia que las utilizadas por los hombres a caballo y, más concretamente, las propias de la caballería pesada (caballos armados). En la práctica, espadas, escudos, lanzas, corazas y yelmos cumplían esencialmente una función material clara, a caballo entre la protección del combatiente y la necesidad de atacar con contundencia al enemigo; pero, al mismo tiempo, eran vehículo de transmisión de toda una serie de cualidades de tipo moral, que subrayaban la distinción social propia de aquél que usaba de tales instrumentos ${ }^{76}$.

Desde el punto de vista técnico, los hombres de armas identificados como caballería pesada debían contar con una plataforma compuesta por dos estribos, una silla con respaldo rígido y una cincha doble para sujetarla a la montura ${ }^{77}$. Además, eran precisos unos sólidos elementos defensivos para el jinete y varios tipos de armas ofensivas. Los elementos básicos del arnés de caballería pesada, a mediados del siglo XIV, presentaban, a diferencia del modelo del caballero altomedieval una mayor presencia de elementos metálicos y una cierta sofisticación al proteger el rostro, las articulaciones y el tórax ${ }^{78}$. Comenzando por la cabeza, el casco o bacinete con sobrecubierta para proteger los ojos, un camal de malla pendiente, un camisote de mallas bajo una jaqueta reforzada en cuero o bien varias corazas metálicas para el torso y la espalda, quijotes, rodilleras y grebas para proteger los muslos, las rodillas y las piernas, respectivamente, con escarpes de láminas metálicas y espuelas en los pies ${ }^{79}$. Respecto a los aparatos ofensivos, el elemento principal era la lanza, que constituía el puntal donde se concentraba la fuerza de montura y jinete en carrera. Además, los caballeros disponían de una espada y, desde el último tercio del siglo XIV, aunque probablemente ya desde antes, del llamado puñal de misericordia ${ }^{80}$.

Los hombres a caballo armados movilizados en Aragón, durante la guerra de los Dos Pedros, utilizaron mayoritariamente cotas de malla frente a las armaduras metálicas de cuerpo entero. Esto no significa que no existieran hombres de armas con los recursos suficientes como para proporcionarse corazas metálicas de torso y espalda, sino que, todavía, este tipo de protección no se había generalizado, algo que, en cualquier caso, se iba a producir en las

75 Maurice Godelier, Lo ideal y lo material. Pensamiento, economías, sociedades, Taurus, Madrid, 1989 (ed. or. 1984), pp. 20-23. Desde el punto de vista de la iconografía, véanse las obras de Pamela Porter, La guerra medieval en los manuscritos, The Britis Library-AyN Ediciones, Madrid, 2000; y Carmen Vallejo Naranjo, La caballería en el arte de la Baja Edad Media, Universidad de Sevilla, Sevilla, 2013.

76 Véanse, por ejemplo, las connotaciones morales asociadas a las principales armas del caballero, en el Libro de la orden de caballeria, de Ramón Llull, ed. Luis Alberto de Cuenca, Alianza, Madrid, 1992, pp. 71-80; y también en la segunda Partida (siglo XIII). Ley cuarta: "Como los cavalleros deven aver en si quatro virtudes principales". Las Siete Partidas del rey d. Alfonso el Sabio, glossadas por el Sr. D. Gregorio López, del Consejo real de las Indias, edición de 1555, corregida y publicada por Joseph Berni y Caralà, Valencia, 1767, pp. 170-171.

77 A. Ayton, "Armas, armaduras y caballos", cit., p. 242. Incluimos una relación de piezas de arnés de caballo en el anexo: tabla 1.

78 El arnés de la caballería pesada altomedieval ha sido descrito, entre otros, por José Ángel Lema Pueyo, Instituciones politicas del reinado de Alfonso I el Batallador, rey de Aragón y Pamplona (1104-1134), Bilbao, 1997, pp. 234-236.

79 Michèle Beaulieu y Jeanne Baylé, Le costume en Bourgogne de Philippe le Hardi à Charles le Téméraire, París, 1956, pp. 146-182; Martí De Riquer, L'arnès del cavaller. Armes i armadures catalanes medievals, Ariel, Barcelona, 1968; y, del mismo autor, Caballeros medievales y sus armas, UNED, Madrid, 1999.

${ }^{80}$ La combinación de fuentes escritas, principalmente inventarios, e iconográficas aporta una enorme cantidad de matices e incluso permite reconocer estilos en la producción de este tipo de armas. Los estudios de caso son muy numerosos y, entre ellos, merece la pena destacar los de Gloria Lora Serrano, "La organización de la defensa militar de un estado señorial y el potencial bélico de un noble a mediados del siglo XV", Historia. Instituciones. Documentos, 18 (1991), pp. 297-338; Alfonso Franco Silva y Álvaro Soler Del Campo, "Los arsenales de dos fortalezas castellanas: inventarios de Torremormojón (1506) y Pedraza de la Sierra (1512)", Historia. Instituciones. Documentos, 21 (1994), pp. 309-344; y M. ${ }^{\text {a }}$ del Rocío Sánchez Ameijeiras, "El arnés y el armamento del caballero medieval gallego (1350-1450)", Acta Historica et Archaeologica Mediaevalia, 10 (1989), pp. 427-436. 
décadas siguientes ${ }^{81}$. Junto a las cotas de malla, existían otros elementos de la indumentaria destinados a proteger el cuerpo del caballero, especialmente las lorigas y, sobre todo, los lorigones, hechos de tejidos gruesos (especialmente de esparto) reforzados con tiras de cuero o pequeñas láminas metálicas. Los lorigones, asimismo, eran las piezas de la indumentaria del caballero que quedaban a la vista y, por lo tanto, solían estar decorados. Durante la guerra con Castilla, Pedro IV dispuso entre sus compañías la colocación de la cruz de San Jorge sobre la indumentaria de los combatientes, tratando de incentivar, mediante esta sanción estética, la mediación divina hacia el triunfo sobre su enemigo ${ }^{82}$. La longitud de cotas y lorigones, podía ser, asimismo, diversa, si bien lo más habitual era que alcanzase hasta la mitad del muslo y que contara con una abertura anterior y otra posterior, desde la cintura hacia las rodillas, a fin de facilitar las maniobras a caballo.

La cabeza y el cuello solían protegerse de manera independiente: para la cabeza se utilizaban yelmos (de visera o no), bacinetes, capellines u otro tipo de cascos, junto a gorgueras para el cuello, o bien otras protecciones tejidas también con la técnica de anillas entrelazadas utilizada en las cotas. Asimismo, la protección de las extremidades se conseguía mediante piezas específicas que, en cierto sentido, preludian ya la armadura del siglo XV. Entre las piezas empleadas, se encuentran los guantes y escarpes metálicos, para manos y pies, respectivamente; así como guardabrazos y grebas para los brazos y las piernas.

Junto a la indumentaria del caballero, se encontraban los elementos exentos, es decir, las espadas, lanzas y escudos. De todos estos objetos, el más valioso, material y simbólicamente, era la espada, un icono preferente de la ideología caballeresca y, por extensión, nobiliaria ${ }^{83}$. Por ello, en todas las casas de la baja nobleza, incluidas las familias de infanzones más humildes, era habitual la existencia de una espada, asociada frecuentemente a un antepasado memorable por su carisma y reconocimiento social. Junto a la espada, el otro arma de ataque empleada por los combatientes de caballería pesada era la lanza, diseñada para concentrar en un punto toda la potencia de la montura y el jinete a la carrera, cuya contundencia en el choque podía llegar a ser demoledora. Las lanzas de este tipo estaban fabricadas sobre un asta de madera endurecida, revestida en su extremo con una punta de metal, afilada y perfectamente encajada. En la parte donde debía sujetarse, la lanza estaba preparada para no deslizarse entre los dedos del jinete y, algo más atrás, podía contar con una pieza que actuase como freno, si bien todavía es difícil hablar de ristres, tal y como fueron diseñados y utilizados desde mediados del siglo XV. De hecho, la iconografía no muestra todavía ejemplos claros sobre la existencia de estas piezas.

El último de los elementos citados es el escudo, utilizado por los combatientes a caballo para desplazar la trayectoria de las lanzas, en el momento de la carga, y para repeler los golpes de las armas de mano, en el momento de la lucha a pie. Los escudos de estos combatientes, a mediados del siglo XIV, presentaban una forma alargada, en vertical, apuntada por la parte in-

81 Algunas de las corazas documentadas estaban revestidas con paños decorados. Por ejemplo, las que fueron pagadas por el armero de Pedro IV, Gil de Lizano, en el segundo semestre de 1356, contaban con su correspondiente "drap de seda estacat". ACA, R.Pat., M.Rac., 782, ff. 41v-42.

82 Las referencias documentales son numerosas, véanse algunas de ellas en Mario Lafuente Gómez, "Devoción y patronazgo en torno al combate en la Corona de Aragón: las conmemoraciones a San Jorge de 1356”, Aragón en la Edad Media, XX (2008), pp. 427-444, concretamente p. 435.

83 Desde la antigüedad, las espadas han sido consideradas como objetos sagrados e incluso litúrgicos, Donald J. Larocca, The Gods of War: Sacred Imagery and the Decoration of Arms and Armor, The Metropolitan Museum of Art, New York, 1996. En la Europa de la alta Edad Media, las espadas eran objetos de oración y, en sus hojas, solían inscribirse plegarias. Jean Flori, Guerra santa, yihad, cruzada. Violencia y religión en el cristianismo y el islam, Universidades de Granada y Valencia, Granda, 2004 (ed. or. 2002), pp. 181-185. Para el contexto hispánico, véase el clásico trabajo de Bonifacio Palacios Martín, "Los símbolos de la soberanía en la Edad Media española. El simbolismo de la espada", VII Centenario del infante don Fernando de la Cerda, 1976, pp. 273-296. 
ferior y truncada por la superior. Su estructura básica estaba construida con listones de madera endurecida, y era reforzada posteriormente con placas de metal y con láminas de cuero, sobre las cuales se plasmaban las armas de su propietario, es decir, los motivos propios de su origen (linaje, ciudad, comunidad, etc.).

Por otra parte, el arnés de los combatientes de caballería ligera era muy diferente del que acabamos de describir. No es fácil saber con exactitud cuáles eran los instrumentos que lo componían debido, sobre todo, a que durante la guerra de los Dos Pedros la perentoria necesidad de defender el reino llevó a movilizar el mayor número de caballerías disponible, haciendo que se contabilizaran como hombres a caballo aforrados a combatientes que, probablemente, no pasarían de ser meros peones montados. No obstante, sabemos que el jinete de un caballo aforrado contaba con una protección menos sofisticada que el de caballería pesada, debido a que su finalidad principal no era cargar, sino desplazarse con agilidad sobre el territorio enemigo. Por ello, solía disponer de un casco (bacinete) y, para cubrir el tronco, de una coraza, una cota de malla o incluso a veces únicamente de una loriga. Como elementos de mano, empleaba también la espada, el escudo y, en ocasiones, una lanza de mano similar a la utilizada por los peones, muy distinta de las de carga que utilizaban los caballeros. Además, podían contar también con mazas, hachas u otras armas menores ${ }^{84}$.

\subsection{El armamento de los peones}

Los hombres que combatían a pie, al igual que los que lo hacían sobre una montura, presentaban en la Edad Media una gran heterogeneidad en cuanto a su equipación. No obstante, todos ellos compartían algunos elementos comunes, especialmente aquellos que servían para proteger el cuerpo del sujeto, comenzando por el casco, entre cuya tipología se encuentra el yelmo (a veces citado como helm) y los capellines. Junto a este elemento, algunos tipos de peones, sobre todo los ballesteros, utilizaban gorgueras similares a las empleadas por los hombres a caballo. Asimismo, sabemos que los peones vestían corazas sobre el torso, generalmente de cuero endurecido y, probablemente, reforzado con placas de metal. La utilización de escudos de mano, sin embargo, no fue un elemento común, sino que estuvo restringido a aquellos peones encargados de combatir directamente, especialmente los lanceros. No obstante, las instrucciones sobre el aprovisionamiento de las fortificaciones incluyeron habitualmente la dotación de paveses, un tipo de escudo de ágil manejo destinado, precisamente, a su uso por parte de los peones en caso de efectuarse un combate cuerpo a cuerpo ${ }^{85}$. Más allá de esta equipación, los elementos empleados por los combatientes a pie exigían una sofisticación que dependía, como veremos enseguida, de aspectos estrictamente técnicos.

De los distintos tipos de peones, los primeros en importancia eran sin duda los ballesteros, cuya función era esencialmente defensiva. De ellos dependía, en gran medida, la defensa de las fortificaciones y la protección de las compañías en sus desplazamiento. Pero su papel era también importante a la hora de atacar una posición o asediar un castillo. La importancia de su

84 Muchas de las piezas citadas en este apartado se incluyen en el inventario que reproducimos en el anexo: tabla 2.

85 Estos utensilios formaban parte con frecuencia de partidas en las que se compraban o se trasladaban de forma conjunta, con el fin de dotar las guarniciones de una fortaleza determinada. Por ejemplo, entre las cuentas presentadas por el tesorero de Pedro IV, Bernat de Ulcinelles, sobre el primer semestre de 1361, se incluye el pago de 33.000 viratones (munición de ballesta), 500 paveses, 200 corazas, 200 capellines y 200 gorgueras de hierro. ACA, R.Pat., M.Rac., 644 (1362, may, 3. Valencia). Los yelmos, citados como helms, figuran en la demanda efectuada por Pedro IV a Ramón de Vilanova, para que enviase 200 de ellos junto a 20 cajas de viratones al castillo de Jaca. ACA, Canc., reg. 1.213, f. 158 (1366, nov, 29. Monells). 
función venía determinada por el potencial del arma que manejaban, es decir, por la ballesta, que permitía lanzar proyectiles (viratones y pasadores) con una gran potencia en distancias medias. Se trata, desde finales del siglo XI, del arma por excelencia de los combatientes a pie, utilizada también en contextos propios de la vida cotidiana como la caza mayor. En cierto modo, la ballesta era el arma del pueblo y, de hecho, muchos concejos llegaron a celebrar, durante la baja Edad Media, juegos y competiciones de ballesta, que cumplían una función paralela a la desempeñada por las justas y torneos entre los grupos aristocráticos ${ }^{86}$.

La importancia de la ballesta queda atestiguada por su constante evolución y perfeccionamiento durante toda la Edad Media. A mediados del siglo XIV, en el reino de Aragón se utilizaban varios modelos. El más habitual era el denominado de cinto o de estribo, es decir, una ballesta de tamaño medio, que pendía de una soga o cuerda gruesa anudada a un cinto de gran resistencia, que el ballestero llevaba rodeando su cintura. Su carga se efectuaba tensando la cuerda con la ayuda de un gancho (croch, croc en catalán actual), mientras el propio ballestero empujaba en sentido inverso el arma con el pie, gracias a un estribo que aquella llevaba colocado al final del cuerpo ${ }^{87}$. Un tipo más sofisticado y menos extendido en estos momentos es la ballesta portátil de torno (o de torn). Estas ballestas contaban también con un estribo en el extremo más alejado del cargador para que el ballestero pudiera sujetarla en el momento de la carga, que, a diferencia del modelo anterior, se efectuaba con el arma puesta en vertical y mediante un torno situado en la parte opuesta al estribo. El torno, por otra parte, era una pieza exenta que se añadía con la única finalidad de tensar la cuerda para la carga ${ }^{88}$.

Respecto a los proyectiles utilizados con las ballestas, existieron al menos tres tipos principales: cuadriellos, viratones y pasadores, sin que podamos establecer un criterio concreto para diferenciarlos. Probablemente, las diferencias entre ellos se encuentren en la forma de sus puntas, metálicas, o en las características de las astas que las sostenían, de madera. Estos proyectiles eran fabricados y distribuidos por miles, entre las distintas fortalezas de la frontera, y las instrucciones en este sentido fueron numerosas ${ }^{89}$. Por otro lado, además de todas las piezas mencionadas, las ballestas podían contar con un utensilio destinado a servir de apoyo y poder afinar, con mayor precisión, el tiro: son las llamadas tallolles de ballesta ${ }^{90}$.

La equipación del resto de los peones era mucho menos sofisticada que la reunida por los ballesteros. Respecto a los lanceros, es preciso indicar que su armamento consistía en una pe-

86 Pedro A. Lillo Carpio, "Notas sobre la ballesta y el cuadrillo en la baja Edad Media", Homenaje al profesor Juan Torres Fontes, Murcia, 1987, v. 1, pp. 871-880.

87 Por ejemplo, en unas instrucciones dirigidas a las huestes procedentes de diversos lugares del Pirineo aragonés, Pedro IV ordenaba que cada uno dispusiera de "bona ballesta ab dues cordes e amcorda, cinto e L viratons". ACA, Canc., reg. 1379, f. 128v (1357, ene, 30. Zaragoza). Los ganchos de cargar ballestas o crochs aparecen mencionados, por ejemplo, en ACA, Canc., reg. 1150, ff. 261v-262 (1357, may, 1. Épila).

88 La coexistencia de las ballestas antiguas, denominadas de cinto o de estribo, con las de torno, más sofisticadas, se constata por ejemplo en el traspaso de la alcaidía del castillo de Cella (Teruel), entre Ramón de Castellón y García de Lecina. En el momento de la cesión, Pedro IV ordenaba al primero hacer entrega al nuevo alcaide de, entre otras cosas, "tots sengles ballestes, axi torns com destrep e los torns d'aquelles, viratonos e aliis qualis se vol armes que a vos foren livrades per defension del dit castell". ACA, Canc., reg. 1.463, f. 124v (1359, nov., 12. Cervera). Y, a su vez, los mismos utensilios se citan con motivo del traspaso del castillo a un nuevo alcaide, Francisco Garcés de Marcilla, al año siguiente: "todas e cada unas ballestas, assi de torno como d'estripera, e los tornos d'aquellas, viratones e otras qualesquiere armas que a vos fueron livradas por deffension del dito castiello o vos tenedes por razon d'aquell”. ACA, Canc., reg. 1.463, f. 131v (1360, abr., 24. Zaragoza).

89 Por ejemplo, el envío de sendos lotes de 5.000 y 2.000 pasadores a Borja, junto a otras herramientas que sugieren su uso con ballestas de estribo (ganchos, paveses, etc.) en ACA, Canc, reg. 1.156, f. 3 (1357, ago., 1; sep., 1. Zaragoza). También los viratones aparecen, con frecuencia, asociados a las ballestas de estribo y gancho, por ejemplo en ACA, R.Pat., M.Rac., 782, ff. 130-130v (contabilidad del primer semestre de 1357).

90 Dos de estos objetos fueron enviados al castillo de Echo (Huesca) en el segundo semestre de 1363. ACA, R.Pat., M.Rac., 888, f. 13. 
queña lanza o azagaya, que servía no sólo para herir, sino sobre todo para despojar del arnés a los adversarios. El resto del equipo que presentaban consistía en los elementos básicos para proteger cabeza, cuello y torso, aunque no necesariamente, y un pequeño escudo o pavés ${ }^{91}$. Asimismo, al hablar anteriormente de los escudats, hemos indicado que apenas se documentan en el ejército aragonés durante la guerra de los Dos Pedros, probablemente porque su función adquiría sentido cuando se trataba de asediar un castillo. Como hemos apuntado ya, la función de los escudats era proteger a los ballesteros mientras éstos se encontraban cargando sus ballestas, en un combate a campo abierto o durante un asedio. El papel esencialmente defensivo de las compañías de peones en Aragón hizo, sin duda, muy poco necesaria la función de este tipo de peones.

Por último, existe una serie de funciones paralelas a las desarrolladas por los combatientes, que se desarrollaron en torno al asedio y defensa de las fortificaciones y cuya ejecución era decisiva para el éxito de las operaciones. Nos referimos a las acciones de minado, derribo de muros, apertura de puertas, etc..$^{92}$. Al igual que sucede con el caso de los escudats, el hecho de que en Aragón la finalidad prioritaria de los hechos de armas fuese la defensa del territorio redujo considerablemente el despliegue de acciones de este tipo, no obstante, sabemos de la existencia de hombres especializados en ello y, asimismo, de la fabricación y distribución de herramientas destinadas a este tipo de tareas. Entre ellas, martillos, mazos y barras de hierro, así como escaleras de mano fabricadas en madera ${ }^{93}$.

\subsection{Artillería detonada con pólvora}

A mediados del siglo XIV la utilización de la pólvora en máquinas de artillería se encontraba, todavía, en una fase técnica todavía muy temprana y, al menos en el contexto hispánico, su eficacia era todavía muy relativa ${ }^{94}$. Las piezas más extendidas, en este momento, en la Corona de Aragón, eran las llamadas ballestas de trueno (ballestas de tro), asociadas mayoritariamente a la defensa de las villas y ciudades más importantes, y cuya forma y funcionamiento siguen siendo difíciles de conocer con detalle ${ }^{95}$.

Según todos los indicios, las ballestas de trueno eran un tipo de cañón todavía muy primitivo, cuya caña, metálica estaría compuesta por dos piezas encajadas longitudinalmente y sujetas con sogas o piezas de madera. La fabricación de estos instrumentos exigía una notable destreza técnica, todavía poco difundida a finales de la década de 1350. Los únicos maestros

91 No hemos documentado, por el momento, la utilización de mazas por parte de los peones aragoneses en este contexto. Sin embargo, no cabe duda de que era un arma relativamente extendida en la época, ya que se servían de ella, por ejemplo, los porteros del rey, y, por otro lado, la iconografía muestra abundantes ejemplos de su uso. Al igual que en el caso de los arneses de caballo y del equipamiento de los hombres de armas, puede verse una relación de las piezas citadas en este apartado en el anexo: tabla 3.

92 Un análisis específico de estas funciones en L.W. Marvin, "Men famous in combat and battle", cit., pp. 243-258.

93 A comienzos de la guerra, por ejemplo, uno de los miembros de la casa del rey, Bernat Porta, recibió cerca de 3.500 sj para comprar "martells de ferre, parpals, barres de ferre, escales de fust e altres arneses necessaris". ACA, R.Pat., M.Rac., 782, f. 322 (segundo semestre de 1357). Algunas de estas herramientas se citan en el anexo: tabla 5.

94 Sobre la evolución del uso de la pólvora en la baja Edad Media, véase Philippe Contamine, La guerra en la Edad Media, Barcelona, 1984. Cap. IV: "Las compañías de aventureros. La artillería y la pólvora. Los ejércitos permanentes (comienzos del siglo XIV-finales del XV)", pp. 154-222; Michael Prestwich, "La revolución de la pólvora, 1300-1500", La guerra en la Edad Media, ed. Matthew Bennet, Akal, Madrid, 2010 (ed. or. 2009), pp. 182-203; y Maurice Keen, "Armas de fuego, pólvora y ejércitos permanentes", Historia de la guerra en la Edad Media, ed. M. Keen, Antonio Machado Libros, Madrid, 2005 (1 $1^{\text {a }}$ ed. 1999), pp. 347-368.

95 Por ejemplo, a mediados de 1363, Pascual Muñoz, herrero y ciudadano de Barcelona, recibió de la tesorería dos ballestas de tro para llevarlas a Zaragoza. ACA, R.Pat., M.Rac., 784, f. 83v (1363, jun. Barcelona). 
especializados en construir estos instrumentos documentados por el momento se encontraban en Barcelona, desde donde hubieron de trasladarse a Zaragoza, por orden del rey, en $1363^{96}$. Junto a ellos, otros artesanos, en su mayoría herreros, intervinieron en la fabricación de estas armas, proporcionando piezas concretas. Por ejemplo, varios herreros zaragozanos, mudéjares, además de dedicarse a fabricar todo tipo de piezas para armas (especialmente puntas de saeta y viratón), colaboraron también en el acabado de algunas ballestas de trueno ${ }^{97}$.

Por otro lado, es preciso señalar que el valor económico de estas piezas, cuando se ha podido documentar, nos lleva a pensar en que la calidad de las mismas podía ser muy heterogénea. Así, tan sólo encontramos algunos ejemplos de ballestas cuyo precio se puede considerar realmente elevado, como las compradas por Antonio Bonell en Barcelona en 1358, cuyo precio probablemente rondó los 700 sueldos barceloneses por unidad ${ }^{98}$. En otras ocasiones, las piezas que componían la ballesta se adquirían por separado, de forma que podemos conocer, por ejemplo, la existencia de creces o pilotes, es decir, de las barras que impulsaban el proyectil, fabricadas en plomo y hierro ${ }^{99}$. Este tipo de piezas se deterioraban a los pocos usos, de modo que era preciso reponerlas con regularidad ${ }^{100}$. Por otro lado, los proyectiles empleados incluían balas de piedra o de plomo, así como espinas de hierro, a modo de metralla ${ }^{101}$.

\section{CONCLUSIÓN}

En las páginas precedentes, hemos tratado de describir y analizar algunos de los aspectos técnicos que rodearon el despliegue militar efectuado en el reino de Aragón entre 1356 y 1366. Concretamente, nos hemos interesado por aquellos elementos relacionados con la tipología de los combatientes y los arneses y armas que aquellos manejaron. No cabe duda de que el tema no está, para nada, agotado, sino que más bien exige de nuevos análisis que contribuyan a integrar, en la medida de lo posible, el repertorio de cuestiones planteadas aquí en el ámbito de la economía (producción y distribución de armas y monturas en los mercados internacionales), la arqueología (estilos y materiales) e incluso la antropología cultural (semiótica y simbología).

Seguramente, la conclusión más relevante que cabe extraer de todo lo dicho sea que, desde el punto de vista técnico, la guerra de los Dos Pedros se asemejó más a la forma de combatir extendida en la Península Ibérica, durante la gran expansión feudal del siglo XIII, en las zonas de fricción entre los reinos feudales y los poderes islámicos, que a la imagen de las grandes batallas de la guerra de los Cien Años — sirvan de ejemplo las de Nájera, 1367; Aljubarrota, 1385 o Azincourt, 1415-. En efecto, aquella guerra guerreada de cabalgadas y asaltos por sorpresa, de prolongados sitios y sufridas resistencias, constituyó también la dinámica general en la que se sumergieron los ejércitos aragonés y castellano entre 1356 y $1366^{102}$. De ahí el pro-

96 ACA, R.Pat., M.Rac., 784, f. 163 (1363, abr, 24; y may, 6. Barcelona). Otras veces, las ballestas eran compradas en Barcelona y trasladadas desde allí, por ejemplo, ACA, R.Pat., M.Rac., 782, ff. 317-317v (1358, ago., 31. Barcelona).

97 Concretamente, Mahoma y Jucef Raffachon. ACA, R.Pat., M.Rac., 782, f. 138v (1357, ago., 14. Cariñena).

98 Antonio Bonell, maestre d'alarotges, recibió de la tesorería del rey $1.463 \mathrm{sb}$ y 8 reales de oro para pagar dos ballestas de tro destinadas a Magallón. ACA, R.Pat., M.Rac., 782, f. 317 (1358, ago., 31. Barcelona).

99 Algunas de las piezas que componían estos ingenios se detallan en el anexo: tabla 4.

100 Tres ballestas de tro contaban con 18 creces o pilotes. ACA, R.Pat., M.Rac., 782, f. 138v (1357, ago., 14. Cariñena).

101 Espinachs de hierro, como las vendidas por Mahoma Raffachon en Zaragoza. Este tipo de munición se comercializaba por millares, concretamente, a $96 \mathrm{~s} 8$ dj el millar, en el verano de 1357. ACA, R.Pat., M.Rac., 782, f. 138v (1357, ago., 14. Cariñena).

102 Los aspectos tecnológicos de este modo de hacer la guerra están sintetizados en Francisco García Fitz, "Ejército y guerra en la Edad Media hispánica”, en Aproximación a la Historia Militar de España, Ministerio de Defensa, Madrid, 2006, pp. 99-123, especialmente pp. 111-113. 
tagonismo observado en elementos que, en cierto sentido, podemos considerar tradicionales, como las cotas de malla entre los caballeros o las ballestas entre los peones.

No obstante, la técnica militar es una disciplina, para mal o para bien, innovadora y sobre el retrato de tipo clásico que caracteriza la guerra de los Dos Pedros, hemos comprobado que fueron surgiendo con fuerza elementos con un inmenso potencial renovador. Algunos de ellos, como las armaduras de coraza metálica o los arcos, se iban a generalizar en la Península Ibérica muy pronto, durante la guerra civil castellana de 1366-1369, por influencia de las grandes compañías de mercenarios que fueron contratadas bien por Pedro I de Castilla o bien por su rival, Enrique de Trastámara, y sus respectivos aliados. Otros, como la artillería de fuego o la preparación de tropas de infantería, conocieron un desarrollo más lento hasta que, a la larga, terminaron por convertirse en factores decisivos para la evolución técnica de la guerra moderna.

\section{ANEXO: INVENTARIO DE LOS ARNESES Y ARMAS HALLADOS EN EL ALCÁZAR DE TERUEL (ABRIL, 1366)}

Fuente: ACA, R.Pat., M.Rac., 784, ff. 256-256v

Tabla 1. Piezas de arnés de caballo

\begin{tabular}{|l|c|}
\cline { 2 - 2 } \multicolumn{1}{l|}{} & Unidades \\
\hline Sillas de caballero viejas y cortadas & 14 \\
\hline Sillas jinetas & 2 \\
\hline Sillas mulares & 2 \\
\hline $\begin{array}{l}\text { Capazo (cofi) de esparto pequeño con láminas (fulles) de hierro ( } \text { a senyal de } \\
\text { guants) para hacer perpuntes y bridas de caballo }\end{array}$ & 1 \\
\hline Trasera (sagrea) de caballo de cuero y de lienzo & 1 \\
\hline Frontal de caballo de lienzo, con forma de cruz & 1 \\
\hline Perpuntas de caballo delantera y trasera, con señal de Muñoz & 1 \\
\hline Trasera de caballo violeta (blava), con señal de Muñoz & 1 \\
\hline Arnés de caballo, de cuero pintado & 1 \\
\hline
\end{tabular}

Tabla 2. Piezas de arnes y armas de combatiente a caballo

\begin{tabular}{|l|c|}
\cline { 2 - 2 } \multicolumn{1}{l|}{} & Unidades \\
\hline Escudos nuevos, con el campo bermejo y un castillo verde en el centro & 33 \\
\hline Gorgueras de hierro viejas & 15 \\
\hline Capellines & 10 \\
\hline Yelmos con viseras de hierro & 4 \\
\hline Bacinetes de hierro con faldas, a manera de capellina del temps antich & 4 \\
\hline Bacinetes genoveses & 3 \\
\hline Jinetes & 3 \\
\hline Lanzas con hierros & 3 \\
\hline Guantes de lana & 2 \\
\hline Barras de madera de portar pendones & 2 \\
\hline
\end{tabular}




\begin{tabular}{|l|c|}
\cline { 2 - 2 } \multicolumn{1}{c|}{} & Unidades \\
\hline Escudos cortados & 2 \\
\hline Escudo bermejo con dos lobos dorados & 1 \\
\hline Pareja de maneguíes de lana & 1 \\
\hline Pareja de corazas de hierro & 1 \\
\hline Barra de portar un pendonete & 1 \\
\hline Casco (capell) de armar, roto & 1 \\
\hline Pareja de corazas de cuero moreno & 1 \\
\hline Lorigón y faldas de malla inutilizadas & 1 \\
\hline
\end{tabular}

Tabla 3. Piezas de arnés y armas de combatiente a pie

\begin{tabular}{|l|c|}
\cline { 2 - 2 } \multicolumn{1}{l|}{} & Unidades \\
\hline Pasadores y cuadrillos, algunos de ellos de hierro & 37.695 \\
\hline Escudos buenos y malos & 43 \\
\hline Ballestas & 10 \\
\hline Parejas de corazas viejas & 8 \\
\hline Recipientes de pasadores & 8 \\
\hline Ballestas de lena & 6 \\
\hline Escudets de caballero pequeños & 6 \\
\hline Ballestas de torno & 4 \\
\hline Adargas & 4 \\
\hline Parejas de cubiertas de ballestas de cuero & 3 \\
\hline Correas sin brazos & 3 \\
\hline Ganchos (crochs) cortados para estirar cuerdas de ballesta & 3 \\
\hline Lenas de ballesta & 2 \\
\hline Tornos de ballesta & 2 \\
\hline Brazo de ballesta de lena sin cuerda y sin correa & 1 \\
\hline Artificio de parar ballestas, de madera & 1 \\
\hline Ballesta & 1 \\
\hline Pavés cortado & 1 \\
\hline
\end{tabular}

Tabla 4. Piezas de artillería (ingenios)

\begin{tabular}{|l|c|}
\cline { 2 - 2 } \multicolumn{1}{l|}{} & Unidades \\
\hline Cuerdas de ingenios, entre nuevas y viejas, más algunos trozos & 43 \\
\hline Fustes, entre grandes y pequeños & 30 \\
\hline Fundas (fonas) de ingenios & 10 \\
\hline Trozos de hierro aparentemente para ingenios & 6 \\
\hline Ruedas de parar ingenios & 2 \\
\hline Rueda grande para hacer cuerdas de cañón (cordes de canyom) & 1 \\
\hline
\end{tabular}




\begin{tabular}{|l|l|}
\hline Cañón de hierro, de tienda & 1 \\
\hline Recipiente de alquitrán & 1 \\
\hline Peso grande, para pesar piedras de ingenios & 1 \\
\hline
\end{tabular}

Tabla 5. Herramientas y utillaje

\begin{tabular}{|l|c|}
\cline { 2 - 2 } \multicolumn{1}{l|}{} & Unidades \\
\hline Ruedas de carretas & 40 \\
\hline Camastros (cambaxes) castellanos rasgados (esquinçats) y viejos & 19 \\
\hline Picos para picar piedra & 14 \\
\hline Garroteras (garroperas) de hierro & 8 \\
\hline Tendolones de cáñamo & 3 \\
\hline Sacos (matalafs) viejos & 3 \\
\hline Puertas & 3 \\
\hline Capazos de caña podrida & 2 \\
\hline Cofres & 2 \\
\hline Tienda de lienzo y lino & 1 \\
\hline Tallador de tienda & 1 \\
\hline Evangeliario (evangeliste) & 1 \\
\hline
\end{tabular}

Recibido: 04/05/11

Aceptado: 31/01/12 